\title{
The relationship between inflammation and neurocognitive dysfunction in obstructive sleep apnea syndrome
}

\author{
Xiangming Liư ${ }^{1,2}$, Yiming Ma ${ }^{1,2}$, Ruoyun Ouyang ${ }^{1,2}$, Zihang Zeng ${ }^{1,2}$, Zijie Zhan ${ }^{1,2}$, Huanhuan Lu,2, Yanan Cui ${ }^{1,2}$, \\ Zhongshang Dai ${ }^{1,2}$, Lijuan Luo ${ }^{1,2}$, Chenjie He ${ }^{1,2}$, Herui Li ${ }^{1,2}$, Dandan Zong ${ }^{1,2^{*}}$ (1) and Yan Chen ${ }^{1,2^{*}}$
}

\begin{abstract}
Obstructive sleep apnea syndrome (OSAS), a state of sleep disorder, is characterized by repetitive apnea, chronic hypoxia, oxygen desaturation, and hypercapnia. Previous studies have revealed that intermittent hypoxia $(\mathrm{IH})$ conditions in OSAS patients elicited neuron injury (especially in the hippocampus and cortex), leading to cognitive dysfunction, a significant and extraordinary complication of OSAS patients. The repeated courses of airway collapse and obstruction in OSAS patients resulted in apnea and arousal during sleep, leading to $\mathrm{H}$ and excessive daytime sleepiness (EDS) and subsequently contributing to the development of inflammation. IH-mediated inflammation could further trigger various types of cognitive dysfunction. Many researchers have found that, besides continuous positive airway pressure (CPAP) treatment and surgery, anti-inflammatory substances might alleviate $\mathrm{IH}$-induced neurocognitive dysfunction. Clarifying the role of inflammation in $\mathrm{IH}$-mediated cognitive impairment is crucial for potentially valuable therapies and future research in the related domain. The objective of this article was to critically review the relationship between inflammation and cognitive deficits in OSAS.
\end{abstract}

Keywords: OSAS, Microglia activation, Inflammation, Neuroinflammation, Neurocognitive dysfunction, Animal model

\section{Introduction}

Obstructive sleep apnea syndrome (OSAS), characterized by recurrent courses of complete or partial collapse of the upper airway during sleep, is a state of sleep disorder that has become a significant public health problem over time. The features of OSAS include snoring, sleep fragmentations, and excessive daytime sleepiness (EDS). Additionally, the collapse of the upper airway directly leads to repetitive apnea, chronic hypoxia, oxygen desaturation, and hypercapnia [1]. Obesity, age, and gender appear to be three of the most important risk factors associated with OSAS [2]. Due to the advances in

\footnotetext{
*Correspondence: zongdandan0402@csu.edu.cn; chenyan99727@csu.edu.cn ${ }^{1}$ Department of Respiratory and Critical Care Medicine, the Second Xiangya Hospital, Central South University, Changsha 410011, Hunan, China Full list of author information is available at the end of the article
}

diagnostic equipment and evolvement of diagnostic criteria, the prevalence of OSAS in the population has increased with time [3]. The adverse medical conditions associated with OSAS include cardiovascular disease [46] (coronary artery disease, heart failure, atrial fibrillation, hypertension, and stroke), metabolic dysfunction $[7,8]$ (dyslipidemia and diabetes mellitus), and neurocognitive impairment $[9,10]$. Recently, cognitive impairment has been proven to be an important complication of OSAS and deserves enough attention. A broad domain of cognitive functions, including memory, attention/vigilance, and executive function, is involved in this process [9]. Many studies have proven that systemic and neuroinflammation play a crucial role in neurocognitive dysfunction [11-13]. In this article, recent papers concerning the relationship between inflammation and 
cognitive impairment in OSAS will be summarized to further help researchers to understand this problem more clearly.

\section{Inflammation in OSAS}

The main mechanisms of OSAS are hypoxia and oxidative stress; however, several studies have demonstrated that inflammation also plays a crucial role in the occurrence and development of OSAS [14]. Systemic and local inflammation in OSAS patients manifests as a result of chronic intermittent hypoxemia $(\mathrm{CIH})[11,15]$, snoring [16], continuous hypoxia [17], oxidative stress, and sleep fragmentation and deprivation [18-20]. In the last two decades, many studies have investigated the precise interactions between OSAS and inflammation in both adults and children, and some studies have tried to elucidate the potential biomarkers in the presence of OSAS and OSAS-related morbidities [21-23].

\section{Biomarkers of Inflammation}

Data provided by numerous studies have proven that inflammation induced by OSAS might trigger the impairment of the vascular endothelial cells and further modify the structure and function of vessels [24]. This impairment leads to endothelial dysfunction, which contributes to various end-organ morbidities, such as cardiovascular disease, metabolic dysfunction and more importantly, the impairment of neurocognitive function [25, 26]. Serum biomarkers related to inflammation, such as interleukin (IL)-1, IL-6, IL-8, IL-17, IL-23, IL-33, tumor necrosis factor- $\alpha$ (TNF- $\alpha$ ), nuclear factor kappa B (NF$\kappa B)$, interferon $-\gamma($ IFN $-\gamma)$, high mobility group box 1 (HMGB1), high-sensitivity C-reactive protein (hs-CRP), serum amyloid A (SAA), prostaglandin E2 (PGE2), uric acid (UA), nitric oxide (NO), P2X7 receptor (P2X7R), toll-like receptors (TLRs), receptor for advanced glycation end product (RAGE), peroxisome proliferators- activated receptor $\gamma$ (PPAR- $\gamma$ ), intercellular adhesion molecules (ICAM), vascular cell adhesion molecule (VCAM), vascular endothelial growth factor (VEGF), pentraxin-3 (PTX-3), leptin, selectins fibrinogen, NLRP3 inflammasome, myeloid-related protein 8/14 (MRP 8/ 14), monocyte chemoattractant protein-1 (MCP-1), macrophage migration inhibitory factor (MIF), CC motif chemokine ligand 5 (CCL5), cyclooxygenase-2 (COX-2), and inducible nitric oxide synthase (iNOS) are activated in OSAS patients [27-32].

Many studies have suggested that OSAS can result in systemic and local inflammation in OSAS patients (Table 1). A meta-analysis focusing on OSAS and inflammation noted that compared with the control group, OSAS patients presented significantly elevated CRP, TNF- $\alpha$, IL-6, IL-8, ICAM, VCAM, and selectins levels. They found the most prominent inflammatory factors presented in OSAS include IL-1, IL-6, and CRP. Additionally, they found that alterations in cytokine levels were closely correlated with the age, body mass index (BMI), and apnea-hypopnea index (AHI) of the patients [33]. A single-center, cross-sectional study conducted by Bouloukaki and colleagues included 1053 subjects who were free of comorbidities and were grouped according to AHI into control, mild, moderate, and severe groups. They collected venous blood from all subjects to measure the levels of CRP, fibrinogen, erythrocyte sedimentation rate (ESR), and UA. The levels of hs-CRP and fibrinogen were elevated significantly in the severe group compared with those in the mild group. However, no significant difference was found between the mild and moderate groups; the UA levels were significantly different among the other groups. However, no obvious difference was found among the groups for ESR. Interestingly, all of these biomarkers except fibrinogen were correlated with sleep time spent with $\mathrm{SaO}_{2}$ less than 90\% (TST90), and fibrinogen was related to active

Table 1 Biomarkers of inflammation in OSAS patients

\begin{tabular}{|c|c|c|c|c|}
\hline Reference & Number of subjects & Detecting parameter & Cytokines levels alteration & $\begin{array}{l}\text { Cytokines concentrations correlated } \\
\text { with }\end{array}$ \\
\hline Nadeem et al. 2013 [33] & $\begin{array}{l}\text { Meta-analysis of } 2952 \\
\text { OSAS and } 2784 \text { controls }\end{array}$ & $\begin{array}{l}\text { CRP, TNF-a, IL-6, IL-8, ICAM, } \\
\text { VCAM, and selectins }\end{array}$ & $\begin{array}{l}\text { CRP } \uparrow, \text { TNF- } a \uparrow, I L-6 \uparrow, I L-8 \uparrow, \\
\text { ICAM } \uparrow, V C A M \uparrow, \text { and selectins } \uparrow\end{array}$ & Age, BMl, AHI \\
\hline Bouloukaki et al. 2017 [34] & 858 OSAS; 190 controls & $\begin{array}{l}\text { CRP, fibrinogen, UA and } \\
\text { ESR }\end{array}$ & $\mathrm{CRP} \uparrow$, fibrinogen $\uparrow, \mathrm{UA} \uparrow$ & $\begin{array}{l}\text { Gender, } \mathrm{BMI}, \mathrm{AHI}, \mathrm{ODI} \text { and mean } \\
\text { and minimum } \mathrm{SaO}_{2}, \mathrm{TST} 90 \text { and } \\
\text { active somking }\end{array}$ \\
\hline Bozic et al. 2018 [35] & 50 OSAS; 25 controls & TNF-a, IL-6 and hsCRP & 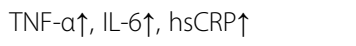 & Plasma adropin levels \\
\hline Motamedi et al. 2018 [36] & 50 OSAS; 24 controls & $\begin{array}{l}\text { Tau, IL-6, IL-10, CRP, TNF- } a \\
\text { and } A \beta\end{array}$ & 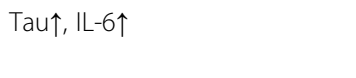 & $\mathrm{AHI}$ \\
\hline Svatikova et al. 2003 [37] & 20 OSAS; 17 controls & SAA & $\mathrm{SAA} \uparrow$ & $\mathrm{AHI}$ \\
\hline Sozer et al. 2018 [38] & 60 OSAS; 24 controls & $\begin{array}{l}\text { CRP, PTX-3, ProCT, IL-33 } \\
\text { and sST2 }\end{array}$ & 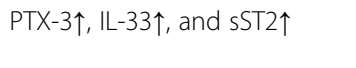 & $\mathrm{BMI}, \mathrm{ODI}$, minimum $\mathrm{SaO}_{2}$ \\
\hline
\end{tabular}

CRP C-reactive protein, TNF- $a$ tumor necrosis factor- $a$, IL interleukin, ICAM intercellular adhesion molecules, VCAM vascular cell adhesion molecule, $B M I$ body mass index, $A H I$ apnea hypopnea index, UA uric acid, ESR erythrocyte sedimentation rate, ODI oxygen desaturation index, TST90 sleep time spent with SaO ${ }_{2}$ less than $90 \%, A \beta$ amyloid beta, SAA serum amyloid A, PTX-3 pentraxin-3, ProCT procalcitonin, sST2 soluble receptor ST2 
smoking [34]. Similar studies conducted by other researchers demonstrated parallel results; CRP was positively correlated with AHI, even adjusted for BMI [39-42].

TNF- $\alpha$ is involved in the regulation of sleep and promotes nonrapid eye movement sleep, and the concentration of TNF- $\alpha$ in human body exhibits circadian patterns [43]. The TNF- $\alpha$ levels increase after undergoing sleep fragmentation and deprivation [22, 44-46]. Bozic et al. [35] screened 50 subjects with newly diagnosed OSAS (25 moderate and 25 severe OSAS patients) and 25 healthy controls. The results showed that the TNF- $\alpha$, IL-6, and hsCRP levels in the severe group were significantly higher than those in the moderate and healthy control groups. Additionally, the subjects harboring the TNF- $\alpha$-308G gene polymorphism tended to exhibit symptoms of daytime sleepiness [47]. Similar results also appeared in obese populations [48].

IL-6 has recently received considerable attention due to its ability to cause vascular inflammation and promote cardiovascular disease, diabetes, and cognitive function deterioration [49-51]. Tau, a microtubule-related protein, is essential for normal neuronal activity and, together with amyloid beta $(A \beta)$, is associated with neurodegenerative processes and neuronal death [52]. $\mathrm{CIH}$ would increase total tau level by upregulating tau phosphorylation in OSAS [26, 53]. Motamedi et al. [36] assessed the levels of tau, IL-6, IL-10, CRP, and TNF- $\alpha$ in three groups (24 healthy control subjects, 22 mild, and 28 moderate-severe OSAS subjects). Compared with the control and mild OSAS groups, the tau and IL-6 concentrations were significantly increased in the severe group. This difference remained significant after adjusting for potential confounding factors such as age, race, gender, and BMI. Additionally, they found that elevated tau levels were associated with AHI. However, no significant difference was found in the TNF- $\alpha$, IL-10, and CRP levels among the three groups. This discrepancy may be related to the small sample size of the survey, younger subject population, and mostly male gender of the subjects.

Furthermore, Svatikova and colleagues performed a study to observe the major acute-phase protein SAA in OSAS patients [37]. They found the SAA levels in moderate to severe OSAS were 2.5-fold higher than those in healthy and mild OSAS subjects. The concentrations of PTX-3, procalcitonin (ProCT), CRP, IL-33, and its soluble receptor ST2 (sST2) were measured to observe their importance as biomarkers in OSAS. Higher levels of PTX-3, IL-33, and ST2 were observed in the OSAS groups than the control group while other cytokines such as ProCT and CRP exhibited similar levels in all groups. Moreover, their data suggested that PTX-3, as an inflammatory factor, may play an important role as an indicator of OSAS severity [38].

\section{Inflammation Levels after CPAP treatment}

CPAP is generally considered a first-line treatment for patients with OSAS. Early use of CPAP can provide patients with maximum functional recovery and minimal residual symptoms [54-58]. Surgery, as a treatment for OSAS patients, is not an alternative to CPAP but a rescue measure after the failure of CPAP or other conservative therapies [59].

Several studies have manifested a significant decline in the level of inflammation in OSAS patients after CPAP treatment (Table 2). A recent meta-analysis concluded that CPAP therapy could significantly decrease the levels of CRP, IL-6, IL- 8 , and TNF- $\alpha$ in OSAS patients. A longer therapy duration ( $>3$ months) and adequate compliance $(\geq 4 \mathrm{~h} /$ night $)$ were also found to more effectively promote a decrease in systemic inflammation [69]. In a large population of CPAP-treated OSAS patients, Schiza et al. [60] assessed the CRP levels for the 12-month follow-up period and found that the concentration of CRP showed a gradual decrease at 3 months with a steep decline at 6 months, reaching a plateau thereafter. They also divided the patients into good and poor compliance groups with CPAP therapy, and the CRP evolution pattern mentioned above was only found in the good compliance group. Relevant conclusions were also reached by Steiropoulos et al. [61] who recruited 52 newly diagnosed OSAS patients and treated them with CPAP. After 6 months of treatment, the patients were divided into 2 groups: good compliance group (mean CPAP use $\geq 4 \mathrm{~h} /$ night) and poor compliance group (mean CPAP use $<4$ $\mathrm{h} /$ night). The serum levels of TNF- $\alpha$ and UA, along with $\mathrm{CD} 4{ }^{+}$cell counts, were only decreased in the former group. These data suggest that the inflammatory levels of the body can only be improved after an adequate CPAP treatment time. Yokoe et al. [62] assessed the concentration of CRP and IL-6 in two groups (30 newly diagnosed OSAS patients and 14 male obese control subjects) and found that the levels of CRP and IL-6 were significantly higher in the OSAS group than in the obese control group. Moreover, after treatment in the OSAS group, significant decreases were observed in the concentration of CRP and IL-6. Another study conducted by Jin and colleagues found increased IL- 8 , TNF- $\alpha$, CRP, ICAM-1, VCAM-1, and selectin levels in the OSAS group [63]. After 3 months of CPAP therapy, the inflammatory factors were significantly decreased. Similarly, several studies demonstrated decreased expression levels of ICAM1, IL-8, HMGB1, and SSA were observed in OSAS subjects who followed CPAP treatment [64-66]. Additionally, the study performed by Lu et al. [67] found elevated levels of NF- $\mathrm{kB}$ and hypoxia-inducible factor- $1 \alpha$ $(\mathrm{HIF}-1 \alpha)$ in OSAS patients that decreased after CPAP treatment. Furthermore, the low level of surfactant protein $\mathrm{D}$ (SPD) in OSAS was increased due to CPAP. 
Table 2 Inflammation levels after CPAP treatment in OSAS patients

\begin{tabular}{|c|c|c|c|c|c|c|}
\hline Reference & $\begin{array}{l}\text { Number of } \\
\text { patients }\end{array}$ & Treatment duration & Daily duration & Detecting parameter & Before treatment & After treatment \\
\hline Schiza et al. 2010 [60] & 528 & 12 months & $\geq 4 \mathrm{~h} /$ night & CRP & $\mathrm{CRP} \uparrow$ & $C R P \downarrow$ \\
\hline Steiropoulos et al. 2009 [61] & 52 & 6 months & $\geq 4 \mathrm{~h} /$ night & $\begin{array}{l}\text { TNF-a, IL-6, UA and CD4 } \\
\text { cell count }\end{array}$ & $\begin{array}{l}\text { TNF-a } \backslash \text { UA } \uparrow \\
\text { CD4 }{ }^{+} \text {cell count } \uparrow\end{array}$ & $\begin{array}{l}\text { TNF-a } \downarrow \\
\text { UA } \downarrow \\
\text { CD4 }^{+} \text {cell count } \downarrow\end{array}$ \\
\hline Yokoe et al. 2003 [62] & 30 & 1 month & NA & CRP, IL-6 & $\begin{array}{l}\text { CRP } \uparrow \\
I L-6 \uparrow\end{array}$ & $\begin{array}{l}C R P \downarrow \\
I L-6 \downarrow\end{array}$ \\
\hline Jin et al. 2017 [63] & 100 & 3 months & NA & $\begin{array}{l}\text { IL-8, TNF-a, CRP, ICAM-1, } \\
\text { VCAM-1, and selectin }\end{array}$ & 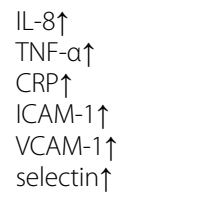 & $\begin{array}{l}\text { IL-8 } \downarrow \\
\text { TNF- } a \downarrow \\
\text { CRP } \downarrow \downarrow \\
\text { ICAM-1 } \downarrow \\
\text { VCAM-1 } \\
\text { selectin } \downarrow\end{array}$ \\
\hline Wu et al. 2010 [64] & 30 & 2 months & NA & HMGB1 and NOx & $\begin{array}{l}\text { HMGB1个 } \\
\text { NOx } \downarrow\end{array}$ & 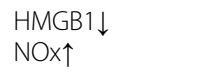 \\
\hline Kuramoto et al. 2009 [65] & 116 & 3 months & NA & SAA, CRP & $\begin{array}{l}\mathrm{CRP} \uparrow \\
\mathrm{SSA} \uparrow\end{array}$ & SAA $\downarrow$ \\
\hline Ohga et al. 2003 [66] & 20 & 8-18 months & NA & ICAM-1, IL-8, MCP-1 & $\begin{array}{l}\mathrm{ICAN}-1 \uparrow \\
\mathrm{IL}-8 \uparrow \\
\mathrm{MCP}-1 \uparrow\end{array}$ & 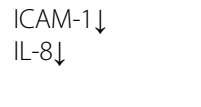 \\
\hline Lu et al. 2017 [67] & 58 & 2 months & NA & $\mathrm{NF}-\mathrm{KB}, \mathrm{HIF-1a}$ and SPD & 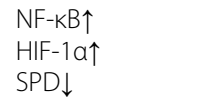 & $\begin{array}{l}\mathrm{SPD} \uparrow \\
\mathrm{NF}-\mathrm{KB} \downarrow \\
\mathrm{HIF-1a \downarrow}\end{array}$ \\
\hline Tichanon et al. 2016 [68] & 13 & 3 months & $\geq 5 \mathrm{~h} /$ night & FeNO, MDA & $\begin{array}{l}\mathrm{FeNO} \uparrow \\
\mathrm{MDA} \uparrow\end{array}$ & $\begin{array}{l}\mathrm{FeNO} \downarrow \\
\mathrm{MDA} \downarrow\end{array}$ \\
\hline
\end{tabular}

CRP C-reactive protein, TNF- $a$ tumor necrosis factor-a, IL interleukin, ICAM-1 intercellular adhesion molecules-1, VCAM-1 vascular cell adhesion molecule-1, UA uric acid, NF-KB nuclear factor kappa B, HMGB1 high mobility group box 1, NOx nitric oxide derivative, SSA serum amyloid A, MCP-1 monocyte chemoattractant protein-1, HIF-1a hypoxia-inducible factor-1a, SPD surfactant protein D, FeNO fractional exhaled nitric oxide, MDA malondialdehyde, NA not administrated

Tichanon et al. [68] assessed airway inflammation by measuring the levels of fractional exhaled nitric oxide (FeNO). Decreased levels of FeNO were observed after 3 months of CPAP treatment in OSAS patients compared with pre-CPAP. However, many studies have failed to document any significant effects of CPAP treatment on inflammatory marker levels. The discrepancy with the results above may be due to the short therapy duration, inadequate compliance, and comorbidities such as cardiovascular disease (CVD). Therefore, more randomized controlled trials, especially those with longer treatment duration, adequate compliance are needed to elucidate the real effects of CPAP on inflammatory response in OSAS patients.

\section{Mechanisms of Inflammation in OSAS}

The increased evidence collected over several years supports that OSAS should be viewed as low-grade chronic inflammatory diseases and the existence of inflammation can be considered a potential contributing factor to OSAS pathophysiology and comorbidity [70]. Numerous studies have established that $\mathrm{CIH}$ [71-73], sleep deprivation [74, 75], and snoring [76] are implicated in the activation and progression of inflammation in OSAS patients. A close link exists between hypoxia and inflammation [73]. Previous works have reported that different organs in the hypoxic environment exhibit different responses at the transcriptional, translational, and post-translational levels [77, 78]. HIF-1 $\alpha$, a pivotal transcription factor in hypoxic induction, activates iNOS gene expression, contributing to increased $\mathrm{NO}$ synthesis. NO plays a critical role in the initiation and regulation of the inflammatory process [79]. Several studies have demonstrated that hypoxia in OSAS may result in adipose tissue inflammation, leading to insulin resistance $[72,80]$. Leptin, a typical biomarker of obesity produced mainly in white adipose tissue, was also increased in OSAS patients [81]. Intermittent hypoxia is a potent stimulator of leptin. The dysregulation of leptin levels promotes oxidative stress and increased production of IL- 6 and TNF- $\alpha$, which are independently induced by OSAS [82]. Effective resolutions of OSAS can lower leptin levels [83]. A systematic review specifically focusing on sleep disturbance and inflammation noted that two inflammatory cytokines, CRP and IL-6, demonstrate a robust association with sleep disturbance [84]. CRP promotes the expression of ICAM and VCAM and induces monocyte-endothelial cell adhesion. CRP upregulates the transcriptional activity of NF- $\kappa B$, triggering a significant increase in ICAM and VCAM [85]. Similarly, the binding of TNF- $\alpha$ and 
tumor necrosis factor receptor 1 (TNF-R1) also stimulates NF- $\mathrm{KB}$ activity, leading to increased expression of VCAM-1 and MCP-1 in endothelial cells [86]. The above changes will subsequently contribute to monocyte-endothelial cell adhesion, intensifying the inflammatory responses in endothelial cells and resulting in the dysfunction of endothelial cells and atherosclerosis. In addition to the evidence mentioned above, age, smoking, obesity, alcohol abuse, infection, and psychosocial stress may also play pivotal roles in the activation of inflammation in OSAS patients.

\section{Cognitive impairment in OSAS}

Cognition function is the process in which the human brain receives external information, processes it, and then transforms it into an intrinsic psychological activity to acquire knowledge and apply it. It includes psychological processes such as memory, attention, reasoning, language, calculation, executive and visuospatial function, and is an important component of human advanced nervous function [87-89]. Various factors, such as older age, gender, smoking, alcohol consumption, diabetes, obesity, hypertension, metabolic syndrome, atherosclerosis, Down syndrome, hypothyroidism, apolipoprotein E epsilon 4 (APOE $\varepsilon 4$ ) allele, cardiac diseases, stroke, active psychiatric drug, and OSAS have been proven to facilitate the onset and progression of cognitive dysfunction [90]. Neurocognitive impairment of OSAS patients, occurring in both adults and children, has an adverse impact on patients' quality of life, learning and work efficiency, and health care utilization.

\section{Brain tissue damage and neurocognitive dysfunction in OSAS}

Systematic and meta-analytic reviews provide robust evidence that OSAS plays a critical role in the emergence and development of a broad spectrum of cognitive dysfunctions: attention and vigilance, verbal and visual delayed long-term memory, visuospatial or constructional abilities, and executive function [9, 91, 92]. OSAS in pediatric populations and adults shows a significant association with attention and vigilance deficits [93-95]. Additionally, many studies have suggested that sustained attention deficits in OSAS patients are positively associated with motor vehicle accident risk [96, 97]. The data provided by several studies revealed significant deficits in verbal but not visual memory [98-100]. A metaanalysis specifically focusing on memory problems in OSAS patients demonstrated significant impairments in immediate and delayed verbal and visuospatial memory and immediate visual recall [101]. Mu et al. [102] using the Memory and Executive Screening (MES) to assess cognitive performance found that the immediate recall capacity is the most sensitive item of cognitive dysfunction. Additionally, a recent meta-analysis [103] revealed that various aspects of executive function (shifting, updating, inhibiting, generativity, and fluid reasoning) were impaired in OSAS patients; moreover, they found that these impairments were improved after CPAP treatment.

By utilizing various imaging technologies to detect the changes appearing in the brains of OSAS patients, an increasing number of studies have suggested that OSAS patients with cognitive impairments are associated with wide-spread structural alterations in diverse brain regions, such as gray and white matter, hippocampus, thalamus, cerebral cortex, brain stem, basal ganglion, frontal, temporal, occipital and limbic lobes, superior frontal gyrus, cingulate gyrus, and cerebellum [104-109]. Many studies have found that compromised gray and white matter integrity is associated with slowed information processing, aberrant emotional functioning, and, more importantly, impaired neurocognitive performance, such as memory, attention, and executive function [110, 111]. Moreover, intermittent hypoxia during sleep in OSAS can contribute to apoptosis and atrophy within the structure of the hippocampus, resulting in learning, mnemonic, attentional, and executive function deficits. Macey and colleagues found the hippocampus exhibits sex-specific regional volume increases and decreases in newly diagnosed, untreated OSAS patients [112]. Similarly, Cross et al. [113] evaluated the cortical thickness and subcortical volumes of the brain by magnetic resonance imaging (MRI) in older adults with or without OSAS. The results showed that oxygen desaturation was significantly associated with reduced cortical thickness in both the left and right temporal lobes, leading to reduced verbal encoding. However, sleep disturbance was correlated with increased thickness in the right postcentral gyrus, pericalcarine, and pars opercularis and increased volume of the hippocampus and amygdala. According to the two studies above, a hypothesis is proposed that the increased thickness of cortex and elevated volume of subcortical structures could be interpreted as enlargement or hypertrophy involving reactive or maladaptive mechanisms, such as cerebral edema, neuronal branching, inflammation, glial activation, or even accumulative $A \beta$ deposition. The disease process may result in decreased thickness and volume due to neuronal cell apoptosis and neuronal tissue atrophy. Moreover, this difference in the thickness and volume of brain structures may indicate a distinct time course within which OSAS exerts detrimental effects on brain integrity. Kim and colleagues used MRI images of the brain to assess local volume changes and, identified atrophy of the neocortex and cerebellum and decreased volume of the hippocampal dentate gyrus and cerebellar dentate nucleus in untreated OSAS patients as well as prefrontal atrophy 
in very severe OSAS patients. Furthermore, they indicated that CPAP treatment is a significant factor correlated with brain structural recovery [114]. Castronovo et al. [115] measured white matter integrity in OSAS patients by diffusion tensor imaging (DTI) and found a decrease in white matter fiber integrity in multiple subdomains of the brain. Moreover, they found that after 12 months of CPAP treatment, both voxel-based morphometry (VBM) and DTI indicated significant improvements in all the affected regions, suggesting that some of the abnormalities are not permanent and can be reversed after effective treatment. Furthermore, the reversibility of the cognitive deficits and corresponding brain morphology changes after treatment have also been confirmed by Canessa et al. [116] using combined neuropsychologic testing and VBM. In the same study, they found a reduced gray matter volume in the left hippocampus (entorhinal cortex), left posterior parietal cortex, and right superior frontal gyrus. After treatment, the increased gray matter volume in the entorhinal cortex, frontal, and parietal structures correlated with improvements in verbal and visuospatial short-term memory, attention, and executive function. Therefore, adherence to treatment such as CPAP and surgery can lead to not only clinical but also brain structural recovery.

\section{Relationship between cognitive dysfunction and OSAS}

Findings from prospective studies of OSAS and cognitive deficits along with results from observational and experimental studies demonstrated that sleep fragmentation and hypoxemia are the two most likely risk factors for cognitive decline $[11,117]$.

A recent meta-analysis demonstrated that individuals exposed to sleep deprivation showed deficits in attention, memory, and general cognition [9]. A study by Zhang et al. [118] found that OSAS plays a significant and independent role in time- and event-based prospective memory deficits in stroke patients. Their data also suggest that sleep disruption and hypoxemia are the two most important predictors of cognitive dysfunction. Similarly, a link between sleep deprivation and impaired attention and memory maintenance has also been demonstrated by Stepan et al. [119]. Additionally, similar deficits in cognitive function were manifested in children exposed to sleep disruption [120]. Recurrence of the cessation of nocturnal breathing leads to repeat arousal during sleep and subsequent excessive daytime sleepiness, which is one of the hallmark characteristics of OSAS patients. A recent review summarized that sleep disruption and daytime sleepiness mainly influenced attention, vigilance, learning, and memory function, and hypoxia has been proven to be an important predictor of frontal impairment and executive deficits [121]. However, in a prospective controlled study, patients with excessive daytime sleepiness only showed executive dysfunction but no other cognitive impairments [122]. Numerous studies have suggested that OSAS-more specifically, hypoxemia-might cause neuronal damage in multiple regions of the brain, especially in the hippocampus and frontal cortex, leading to attention impairments, slow processing speed, and damaged executive functions [123]. In an IH rat model study, Gao and colleagues utilized Morris water maze tasks to assess the influences of $\mathrm{IH}$ exposure on spatial memory and learning performance and found that exposure to $\mathrm{IH}$ resulted in poor performance in the tasks above [124]. Additionally, they found that the expression levels of apoptosis and anti-apoptosis proteins both changed in the hippocampus among the IH exposed rats. In another animal study, the expression of brain-derived neurotrophic factor (BDNF) was reduced significantly in mice exposed to $\mathrm{CIH}$ and the declined level of BDNF is a crucial factor leading to the impairment of long-term hippocampal plasticity and memory function [125]. Furthermore, besides sleep fragmentation and hypoxemia, numerous studies have demonstrated that age, obesity, hypercapnia, intelligence, and heredity also play an important role in neurocognitive dysfunction [126-128].

\section{Role of inflammation in the development of cognitive dysfunction in OSAS}

Compared with other parts of the body, the brain requires more energy and oxygen consumption and is more sensitive to hypoxia [129]. Data provided by previous studies have generally considered that the activation of inflammation in OSAS patients is a major pathological factor associated with CVD, diabetes mellitus, and nervous system diseases such as dementia, Parkinson's disease, Alzheimer's disease, and epilepsy [8, 130, 131]. More importantly, inflammation causes endothelial cell dysfunction and atherosclerosis within the brain, decreasing the brain blood flow and lowering the metabolic function and oxygen consumption in neurons [132]. These changes trigger apoptosis and necrosis of nerve cells and consequently induce various neurocognitive disorders.

\section{Association of inflammation and cognitive dysfunction in OSAS patients}

Because plasma samples are easily available, several studies have measured serum inflammatory biomarker levels and cognitive performance in OSAS patients to observe the association between inflammation and neurocognitive deficits.

The observational study by Huang and colleagues investigated the status of proinflammatory cytokines and cognition in 47 nonobese OSAS children and 32 healthy control children [27]. They respectively examined the 
plasma levels of inflammatory cytokines such as CRP, TNF- $\alpha$, IL-1, IL-6, IL-10, IL-17, and IL-23 and investigated neurocognitive functions using neuropsychological tests such as the Wechsler- $\mathrm{R}$ intelligence (WPPSI-R) intelligence test to assess IQ score, Conners' Kiddie Continuous Performance Test (k-CPT) to measure attention problems, and Wisconsin card sorting test (WCST) to evaluate executive function. The standardized regression test indicated a significant relationship between proinflammatory cytokines and neurocognitive performance. The experiment suggested that elevated cytokines such as CRP, THF- $\alpha$, IL-17, and IL-23 are related to impaired inattention and vigilance abilities. Additionally, the elevated levels of TNF- $\alpha$, IL- 6 , and IL-23 were related to decreases in executive functions. Sun et al. [133] used the Montreal Cognitive Assessment (MoCA), Mini-Mental State Examination (MMSE), and Epworth Sleepiness Scale (ESS) to assess the cognitive status in OSAS patients. They found significant impairments in visual space, attention, executive function, and delayed memory function. Elevated levels of hs-CRP, leptin, and TNF- $\alpha$ were observed in the severe OSAS group. More importantly, after adjusting for confounding factors such as BMI, age, and education years, the MoCA scores exhibited negative correlations with AHI, the oxygen desaturation index (ODI), and TNF- $\alpha$ and a positive correlation with minimum oxygen saturation. Notably, after CPAP treatment, both inflammation and cognitive impairment were improved in OSAS patients. In another study conducted by Haensel et al. [134], 39 patients with untreated sleep apnea were recruited. They assessed the concentrations of IL- 6 , TNF- $\alpha$, and soluble TNF-R1 (sTNF-R1) and evaluated cognitive domains of attention and working memory, executive function, verbal learning and memory, visual learning and memory, and verbal fluency via a series of psychological tests, such as the Wechsler Adult Intelligence Scale-III Digit Symbol, Symbol Search, Digit Span, and Letter-Number Sequencing; Brief Visuospatial Memory Test Revised; Hopkins Verbal Learning Test Revised; Trail Making A/ B; Digit Vigilance Test; Stroop Color-Word Test; and Controlled Oral Word Association Test. Multivariate analyses indicated that only the inflammatory cytokine sTNF-R1 was related to the impaired cognitive function. They also found that sTNF-R1 acted as an important predictor of cognitive status. Taken together, these findings above suggest that the elevated inflammation levels contribute, at least partially, to $\mathrm{CIH}$-mediated neuronal damage and cognitive dysfunction.

\section{Inflammation leading to cognitive deficits in $\mathrm{CIH}$ animals}

Due to the limitations of clinical trials, researchers can only screen for cognitive morbidity via different brain imaging studies and various neuropsychological tests.
Animal models have provided considerable benefits in various studies, particularly, regarding interventions that are difficult or impossible to perform on humans. Animal experiments provide an ideal solution to these problems. Thus far, $\mathrm{CIH}$ mice have been widely used to elucidate the underlying mechanisms of cognitive impairment in OSAS (Table 3).

Dong et al. [135] found the sevoflurane exaggerated microglia-mediated neuroinflammation and aggravated cognitive deficits in $\mathrm{CIH}$ rats via downregulation of PPAR- $\gamma$ in the hippocampus. After IH exposure and administration of sevoflurane, the animals were subjected to the Morris water maze to assess spatial learning and memory and then the levels of proinflammatory cytokines such as TNF- $\alpha, \mathrm{IL}-1 \beta$, and the activity of microglia in the hippocampus were examined. The results showed that microglia activity and TNF- $\alpha$ and IL- $1 \beta$ levels in the hippocampus were increased in $\mathrm{CIH}$ rats, with greater increases in $\mathrm{CIH}+$ sevoflurane rats. Notably, $\mathrm{CIH}+$ sevoflurane rats showed a much longer escape latency to locate the hidden platform and much less time spent in the goal quadrant than the $\mathrm{CIH}$ group. Thus, microgliamediated neuroinflammation exaggerated by sevoflurane in the hippocampus plays an important role in the pathogenesis of $\mathrm{CIH}$-induced cognitive deficits. Sapin and colleagues determined the levels of several inflammatory cytokines and microglial changes in the hippocampus of mice under normoxia or hypoxia conditions [136]. They found that chronic, but not acute IH exposure, induced significant increases in the density and morphological features of microglia priming. However, increased mRNA levels of inflammatory cytokines such as RANTES/CCL 5 and IL- $1 \beta$ were observed in acute but not chronic $\mathrm{IH}$-exposed mice. These changes, including early but transient cytokine alterations and delayed but long-term microglia-mediated inflammation in the hippocampus, may lead to cognitive dysfunction and neurodegeneration in IH mice. Shi et al. [137] and colleagues found that microglia activity, the levels of NF$\kappa B-p 65$, TNF- $\alpha$ and IL- $1 \beta$, and hippocampal neuronal apoptosis were significantly increased after IH exposure. This increased neuroinflammation and brain tissue damage in IH-exposed mice might explain the poor performance in the Morris water maze test. Additionally, they found that HMGB1 secreted by activated microglia was significantly elevated in vitro. Furthermore, Snyder et al. [138] removed the brain tissue from both the $\mathrm{CIH}$ rodent group and normoxia control group to survey the association between inflammation and early-stage neurodegeneration. The $\mathrm{CIH}$ group showed increased inflammation and oxidative stress in brain regions associated with early-stage Alzheimer's disease and Parkinson's disease. Therefore, the results indicated that $\mathrm{IH}$-induced inflammation may be a key feature in early-stage 


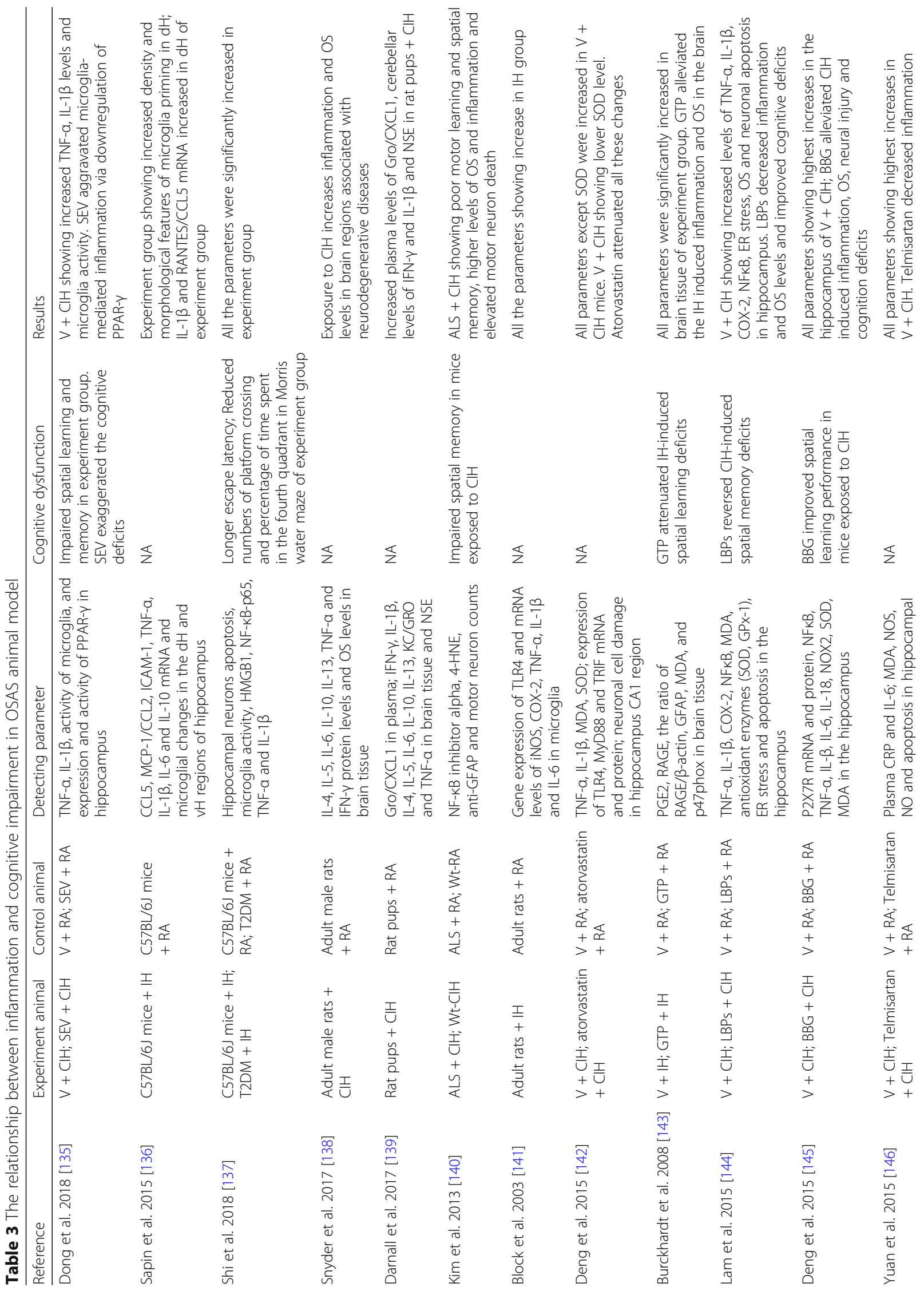




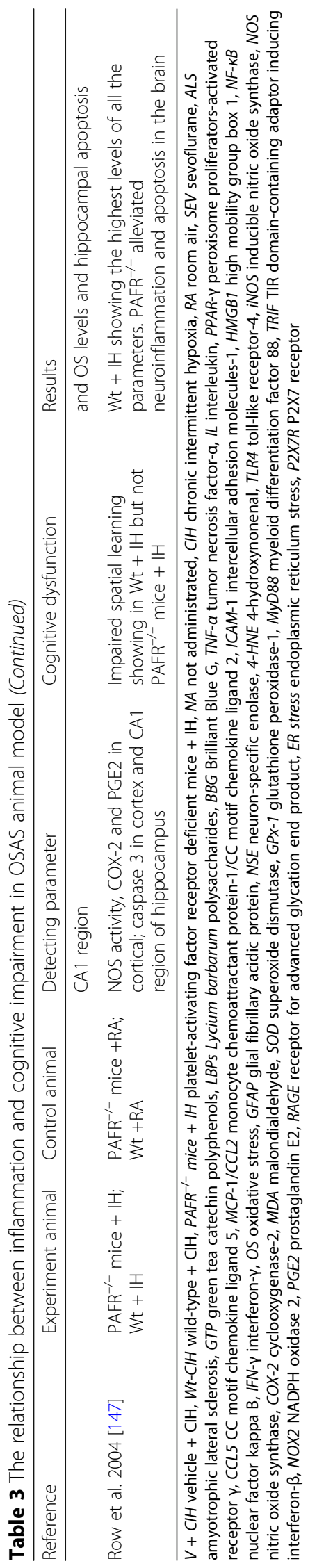


neurodegenerative diseases. Their data also suggest that inflammatory profiles are altered in a brain regionspecific manner in the central nervous system (CNS).

Inflammatory cytokines, brain injury biomarkers, and brain imaging were observed by Darnall et al. [139] to clarify the outcomes of intermittent hypoxia in rodents. Their study showed that the IH-exposed rat pups exhibited increased plasma levels of Gro/CXCL1 and elevated cerebellar IFN- $\gamma$ and IL-1 $\beta$ levels compared with the room air control group. In the IH-exposed rat pups, brain imaging showed decreased white matter integrity. Moreover, neuron-specific enolase (NSE), which is released after neuronal death and traumatic brain injury, was higher in the medullas of $\mathrm{IH}$-exposed rats compared with that in controls. These findings provided evidence that hypoxia-mediated inflammation and brain injury might later manifest as executive deficits. Kim et al. [140] reported that $\mathrm{CIH}$ might aggravate motor learning and spatial memory deficits by lowering the levels of NF- $\kappa B$ inhibitor alpha $(\mathrm{I} \kappa \mathrm{B} \alpha)$ and exaggerate oxidative stress in amyotrophic lateral sclerosis (ALS) mice. Similarly, Block et al. [141] dissected the cortex, medulla, and spinal cord tissues from $\mathrm{IH}$ rats to determine the mRNA levels of inflammatory cytokine TLR4, which plays an important role in the regulation of inflammation. The results presented that $\mathrm{IH}$ treatment increased inflammatory gene expression, including that of iNOS, COX-2, TNF- $\alpha$, IL- $1 \beta$, and IL- 6 , in different brain regions. Additionally, the mRNA levels of TLR4 were significantly upregulated by IH and the increase in TLR4 expression is consistent with the timing of peak inflammatory gene expression, suggesting that TLR4 serves as an essential factor in $\mathrm{IH}$-induced inflammation.

Findings from clinical and animal studies demonstrated that inflammation might play a crucial role in neuronal cell injury and consequent cognitive impairments associated with $\mathrm{CIH}$. Both clinical and animal experiments demonstrate learning and memory deficits. Impaired attention/vigilance and executive function were only found in clinical studies. Elevated plasma and brain tissue CRP, IL-1 $\beta$, IL-6, TNF- $\alpha$, HMGB1, NF-kB, TLR4, and COX-2 levels were observed in $\mathrm{CIH}$ animal models. These inflammatory cytokine alterations in animal studies are consistent with the changes in human plasma. Additionally, animal experiments demonstrated increased microglial activation and neuronal apoptosis in various regions of the brain. CPAP has been proven to alleviate $\mathrm{CIH}$-mediated inflammation and cognitive dysfunction in clinical studies.

\section{Potential mechanisms between inflammation and neurocognitive dysfunction}

As discussed previously, OSAS can lead to peripheral and neural inflammation. The relationship between an excessive inflammatory response and impaired cognitive function has been documented in many other diseases, such as sepsis, Alzheimer's disease, post-operative cognitive dysfunction (POCD), traumatic brain injury, and spinal cord injury [148-151]. Based on the existing evidence, the relationship between inflammation and cognitive dysfunction in OSAS can be inferred as shown in Fig. 1.

The blood-brain barrier (BBB) is a physical and biochemical barrier that isolates the CNS from the peripheral environment. It plays an important role to maintain cerebral homeostasis [152]. Due to the protective effect of $\mathrm{BBB}$, the CNS was previously thought to be impervious to peripheral inflammation. However, the recent discovery of the bidirectional crosstalk between peripheral and neural inflammation has challenged this assumption [153]. Cumulative evidence has suggested that peripheral inflammation is a major factor that can lead to neuroinflammation by damaging endothelial cells, disrupting the integrity and permeability of the BBB [154]. Many studies have documented that the release of TNF- $\alpha$ and downstream NF- $k B$ can breach the $B B B$, facilitate the migration of macrophages into the hippocampus, activate glial cells, and eventually lead to cognitive deficits after peripheral surgery $[155,156]$. The elevated serum levels of HMGB1 in sepsis may also act on cerebral microvascular endothelial cells, compromise the integrity of $\mathrm{BBB}$, expose the brain to neurotoxic substances, and finally contribute to cognitive dysfunction [151]. Additionally, the BBB can selectively transport several inflammatory cytokines such as IL-1 $\beta$, IL-6, and TNF- $\alpha$-via specific receptors and transporters in cerebral endothelial cells [157]. Additionally, inflammatory cytokines can also access the brain through the circumventricular region where the BBB is discontinuous [158]. Notably, some studies have found that peripheral cytokines directly stimulate the vagal afferents to convey the peripheral immune signals to the CNS [159].

Glial cells are another large category of cells in the CNS besides neurons. Microglia, as resident immune cells of the CNS, play an important role in the regulation of inflammation in the brain. Neuroinflammation is specifically manifested by glial cell activation. $\mathrm{CIH}$ and the invasion of peripheral inflammatory factors activate microglia and astrocytes, which secrete cytokines, such as IL-1 $\beta$, IL- 6 , TNF- $\alpha$, and HMGB1, oxidative species, adhesion molecules, and other signalling mediators [160]. Many studies have documented that the high levels of cytokines produced by microglia and astrocytes can aggravate neuronal axon and synaptic damage, increase demyelination, and impair the integrity of white matter in multiple CNS regions $[160,161]$. The 


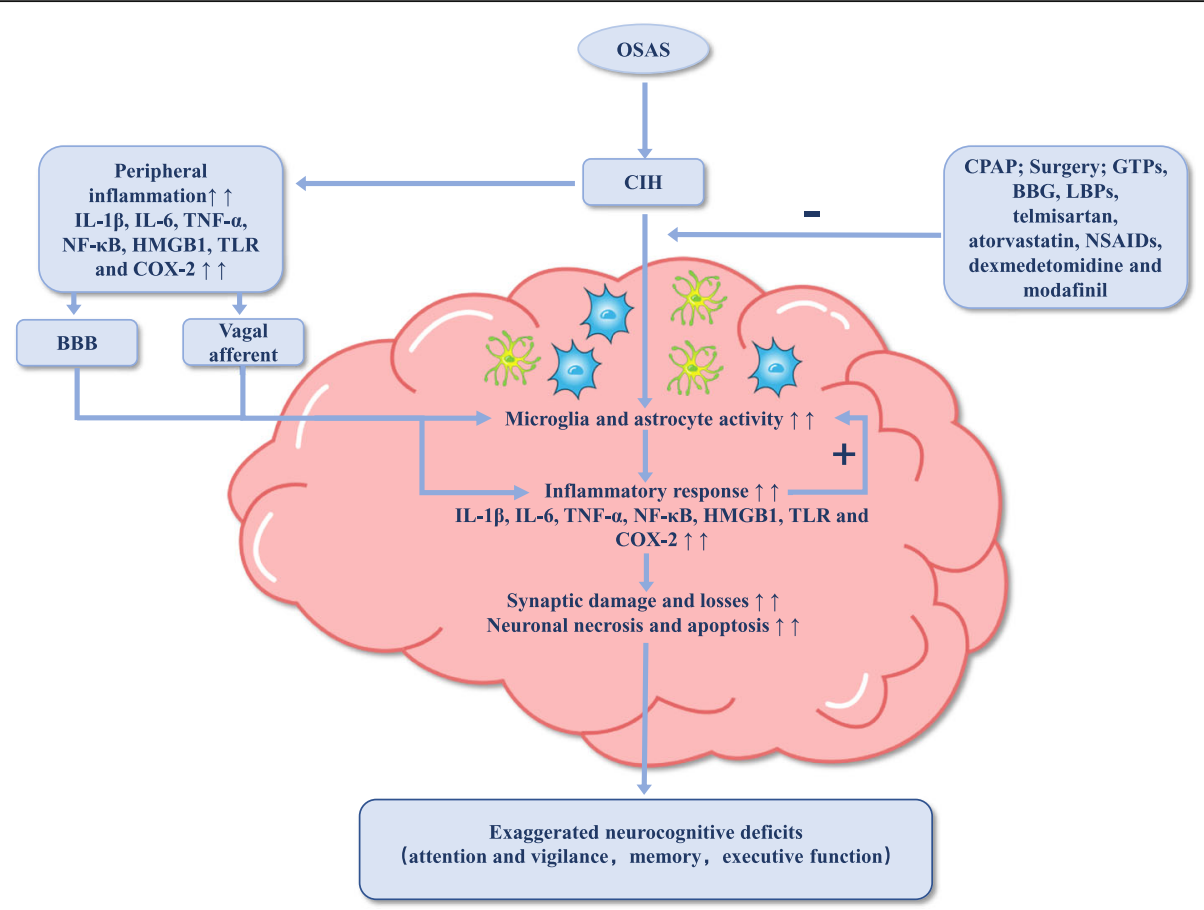

Fig. 1 Inflammation and cognitive deficits in OSAS. This figure demonstrates the important role played by inflammation in OSAS related cognitive dysfunction. $\mathrm{CIH}$ characterized in OSAS leads to peripheral inflammation which access the CNS through BBB or via the stimulation of vagal afferents. The high level of inflammation in the CNS further upregulates glial cells (microglia and astrocyte) activity, inducing and aggravating the neuroinflammatory reaction. Meanwhile, $\mathrm{ClH}$ could directly activate microglia and astrocyte, prompting the release of inflammatory cytokines in the CNS. The excessive neuroinflammatory response could in turn boost the activation of glial cells, lead to synaptic damage and losses, neuronal necrosis and apoptosis, and ultimately result in exaggerated neurocognitive deficits. In addition, treatment with CPAP, surgery, and administration of GTPS, BBG, LBPs, telmisartan, atorvastatin, NSAIDs, dexmedetomidine, and modafinil would alleviate the neuroinflammation and improve cognitive function. CIH chronic intermittent hypoxia, CNS central nervous system, BBB blood-brain barrier, CPAP continuous positive airway pressure, GTPs green tea catechin polyphenols, BBG Brilliant Blue G, LBPS Lycium barbarum polysaccharides, IL interleukin, TNF-a tumor necrosis factor-a, NF-KB nuclear factor kappa B, COX-2 cyclooxygenase-2, NSAIDs non-steroidal anti-inflammatory drugs

cytokines released by glial cells can further disrupt the $\mathrm{BBB}$, and activate glial cells, leading to a vicious cycle. Evidence has shown that the inflammatory responses in an animal model of surgery result in decreased levels of BDNF, which is crucial in multiple aspects of neural plasticity $[125,162]$. Hippocampus, which is implicated in learning and memory function, appears particularly vulnerable to excessive neuroinflammation due to abundant receptors such as IL- $1 \beta$ receptor, TNF- $\alpha$ receptor, and HMGB1 receptor in this region [163]. These researches gave us a much more distinct view on the relationship between the inflammatory status and the potential relationships with specific cognitive functions. However, the mechanism between inflammation and cognitive decline has been rarely mentioned in OSAS and was mainly discussed on other diseases, such as Alzheimer's disease, POCD, and sepsis. Therefore, further clinical and animal experiments are required to clarify the precise mechanism and specific signaling pathways involved in the pathogenesis of OSAS-mediated brain structural damages and cognitive alteration.

\section{Potential therapies for inflammation-mediated neurocognitive dysfunction}

Numerous studies have examined various endogenous factors and exogenous substances that would protect brain tissues from $\mathrm{CIH}$-induced neuroinflammatory impairment. Many anti-inflammation drugs and substances can effectively suppress the inflammatory process and improve cognitive dysfunction. Intracerebroventricular injection of anti-HMGB1 antibody can inhibit the synthesis of inflammatory cytokines, microglia activation, and neuronal damage in the hippocampus after status epilepticus [164]. Terrando et al. demonstrated that the blockade of TNF- $\alpha$ leads to lower levels of downstream IL-1, alleviates neuroinflammation, and improves neurocognition in an animal model of surgery-induced cognitive decline [165]. Similarly, in a rat experiment, intracisternal administration of IL-1 receptor antagonist inhibited neuroinflammation and cognitive decline after surgery [166]. TLR, a critical immune receptor that binds specifically to pathogen-associated molecular patterns (PAMPs) to mediate inflammatory reaction, is associated with almost all inflammation-related diseases. 
Administration of a TLR-4 receptor antagonist also plays a role in improving neuroinflammation and cognition in an Alzheimer's disease mouse model [150]. Nonsteroidal anti-inflammatory drugs (NSAIDs) block the synthesis of prostaglandins by inhibiting cyclooxygenase enzymes (COX-1 and COX-2), thereby suppressing inflammatory activities [167]. Numerous studies have found that high levels of cytokine expression (IL-1 $\beta$, IL-6, and TNF- $\alpha$ ), glial activation, hippocampal microgliosis, and cognitive deficits are ameliorated by the administration of NSAI DS such as ibuprofen, paracetamol, and parecoxib in animal models [168-170].

In addition to the anti-inflammatory drugs mentioned above, dexmedetomidine, an $\alpha 2$ adrenoceptor agonist, can lower the levels of IL-1 $\beta$, IL-6, TNF- $\alpha$, and TLR- 4 in the hippocampus, reduce the activity of glial cells, and reverse neurodegenerative and neuronal apoptosis, thus improving cognitive function [171, 172]. Deng et al. [142] found that atorvastatin, which regulates the expression of TLR4, attenuated neuronal damage and decreased the elevation of TLR4 together with downstream inflammatory cytokines such as TNF- $\alpha$ and IL- $1 \beta$ in the hippocampus. Green tea catechins polyphenols (GTPs) extracted from green tea could alleviate $\mathrm{IH}$-induced spatial learning deficits. Moreover, the GTPs also decreased the high levels of inflammation and OS in IHexposed animals [143]. Similarly, Lam et al. [144] demonstrated that Lycium barbarum polysaccharides (LBPs) play a neuroprotective role in $\mathrm{IH}$-induced, cognitionimpaired rats. Their study showed that LBPs significantly lower the high levels of inflammation and OS in subfields of the hippocampus, prevent autophagic flux and apoptosis induced by hypoxia, and attenuate $\mathrm{IH}-$ mediated spatial memory deficits in IH rat models. Brilliant Blue G, a selective P2X7R antagonist, was confirmed to prevent $\mathrm{IH}$-induced neuronal cell apoptosis and spatial learning deficits by inhibiting inflammation and oxidative stress in the hippocampus of $\mathrm{CIH}$ murine models [145]. Telmisartan, an angiotensin II type 1 receptor blocker, exerts protective effects on hippocampus damage induced by $\mathrm{CIH}$. Yuan and colleagues utilized TUNEL staining for apoptotic cells to evaluate hippocampal injury [146]. They found that treatment with telmisartan effectively ameliorates $\mathrm{CIH}$-induced hippocampal apoptosis. Moreover, their data demonstrated that treatment with telmisartan suppressed the elevated levels of inflammation and OS in the peripheral blood and hippocampus of $\mathrm{CIH}$ rat models. This finding suggests that the neuroprotective effects of telmisartan may be mainly due to the inhibition of inflammation and oxidative stress levels. Platelet-activating factor (PAF), an endogenous proinflammatory phospholipid, is synthesized in the CNS [173]. Row et al. [147] found that IH-exposed PAF receptor-deficient mice showed lower inflammation levels, better neurocognitive function, and less neuronal apoptosis than wild-type $\mathrm{IH}$ mice. These findings demonstrate that $\mathrm{IH}$-induced neuron injury and cognitive deficits are mediated by PAF receptor via the activation of COX-2 and iNOS in the brain tissue. Notably, modafinil, a psychostimulant drug mainly used in the treatment of sleep disorders, was recently found to have neuroprotective effects. Modafinil can alleviate neural and systemic inflammation by inhibiting the activation of microglial and infiltration of leukocytes into the CNS, thereby reversing neurological disorders in animal models [174]. These neuroprotective substances may be a promising therapeutic method to alleviate OSAS-mediated cognitive impairments and more studies are needed in the future to verify this link.

\section{Conclusion}

Repeated courses of airway collapse and obstruction in OSAS patients induced recurrent apnea and periodic arousal during sleep, leading to IH and EDS and contributing to the occurrence and development of neuroinflammation and consequent neurocognitive impairments. Because the hippocampus and cortex are most sensitive to hypoxia, most neurocognitive dysfunctions are related to these two regions. Inflammatory cytokines including IL-1 $\beta$, IL-6, TNF- $\alpha$, NF- $\kappa$ B, HMGB1, and COX-2 are involved in the development of neurocognitive deficits in OSAS patients. Treatment with CPAP, atorvastatin, telmisartan, GTPs, Brilliant Blue G, LBPs, and anti-inflammatory substances can attenuate the IH-induced neuroinflammation, leading to better neurocognitive function. These findings suggest an intimate link between inflammation and cognitive impairment in OSAS and provide a novel direction for the treatment of related disorders in the future.

\footnotetext{
Abbreviations

OSAS: Obstructive sleep apnea syndrome; $\mathrm{ClH}$ : Chronic intermittent hypoxia; CPAP: Continuous positive airway pressure; EDS: Excessive daytime sleepiness; IL: Interleukin; hs-CRP: High-sensitivity C-reactive protein; TNFa: Tumor necrosis factor-a; NF-kB: Nuclear factor kappa B; ICAM: Intercellular adhesion molecules; VCAM: Vascular cell adhesion molecule; VEGF: Vascular endothelial growth factor; MCP-1: Monocyte chemoattractant protein-1; MIF: Macrophage migration inhibitory factor; CCL5: CC motif chemokine ligand 5; COX-2: Cyclooxygenase-2; MRP 8/14: Myeloid-related protein 8/14; P2X7R: P2X7 receptor; IFN-ץ: Interferon- $\gamma ;$ HMGB1: High mobility group box 1 ; SSA: Serum amyloid A; PPAR- $\gamma$ : Peroxisome proliferators-activated receptor $\gamma$; PTX-3: Pentraxin-3; PGE2: Prostaglandin E2; UA: Uric acid; NO: Nitric oxide; iNOS: Inducible nitric oxide synthase; TLRs: Toll-like receptors; RAGE: Receptor for advanced glycation end product; BMI: Body mass index; AHI: Apnea hypopnea index; ESR: Erythrocyte sedimentation rate; TST90: Sleep time spent with $\mathrm{SaO}_{2}$ less than 90\%; Aß: Amyloid beta; ProCT: Procalcitonin; HIF1a: Hypoxia inducible factor-1a; FeNO: Fractional exhaled nitric oxide; CVD: Cardiovascular disease; TNF-R1: Tumor necrosis factor receptor 1; APOE ع4: Apolipoprotein E epsilon 4; MRI: Magnetic resonance imaging; DTI: Diffusion tensor imaging; VBM: Voxel-based morphometry; BDNF: Brainderived neurotrophic factor; ODI: Oxygen desaturation index; CNS: Central nervous system; NSE: Neuron-specific enolase; IkBa: NF-kB inhibitor alpha; ALS: Amyotrophic lateral sclerosis; POCD: Post-operative cognitive dysfunction; BBB: Blood-brain barrier; PAMPs: Pathogen-associated molecular
} 
patterns; NSAIDs: Nonsteroidal anti-inflammatory drugs; GTPs: Green tea catechins polyphenols; LBPs: Lycium barbarum polysaccharides; PAF: Plateletactivating factor; MDA: Malondialdehyde; OS: Oxidative stress; SOD: Superoxide dismutase; $\mathrm{NOX}_{2}$ : NADPH oxidase 2; 4-HNE: 4Hydroxynonenal; TRIF: TIR domain-containing adaptor inducing interferon- $\beta$; GPx-1: Glutathione peroxidase-1; MyD88: Myeloid differentiation factor 88

\section{Acknowledgements}

Not applicable.

\section{Authors' contributions}

$X \mathrm{~L}, \mathrm{YM}, \mathrm{ZZ}, \mathrm{ZZ}, \mathrm{HL}, \mathrm{YC}, \mathrm{ZD}, \mathrm{LL}, \mathrm{CH}$, and $\mathrm{HL}$ designed the drafting, acquired the materials, and wrote the manuscript draft. OR edited and revised the manuscript. DZ and YC reviewed and edited the manuscript. All authors read and approved the final manuscript for publication.

\section{Funding}

This study was supported by grants from the Natural Science Foundation of Hunan Province (Grant No. 2018JJ3763) and the National Natural Science Foundation of China (Grant No. 81900042, No. 81873410) and the National Key Clinical Specialty Construction Projects of China (Grant No. 2012-650).

\section{Availability of data and materials}

The data supporting the conclusion of this article is included within the "References" section.

\section{Ethics approval and consent to participate} Not applicable.

\section{Consent for publication}

Not applicable.

\section{Competing interests}

The authors declare that they have no competing interests.

\section{Author details}

${ }^{1}$ Department of Respiratory and Critical Care Medicine, the Second Xiangya Hospital, Central South University, Changsha 410011, Hunan, China. ${ }^{2}$ Research Unit of Respiratory Disease, Central South University, Changsha 410011, Hunan, China.

Received: 24 March 2020 Accepted: 20 July 2020

Published online: 01 August 2020

\section{References}

1. Andaku DK, D'Almeida V, Carneiro G, Hix S, Tufik S, Togeiro SM. Sleepiness, inflammation and oxidative stress markers in middle-aged males with obstructive sleep apnea without metabolic syndrome: a cross-sectional study. Respir Res. 2015;16:3

2. Garvey JF, Pengo MF, Drakatos P, Kent BD. Epidemiological aspects of obstructive sleep apnea. J Thorac Dis. 2015;7:920-9.

3. Franklin KA, Lindberg E. Obstructive sleep apnea is a common disorder in the population-a review on the epidemiology of sleep apnea. J Thorac Dis. 2015;7:1311-22

4. Kim T, Lee CS, Lee SD, Kang S-H, Han JW, Malhotra A, Kim KW, Yoon I-Y. Impacts of comorbidities on the association between arterial stiffness and obstructive sleep apnea in the elderly. Respiration. 2015;89:304-11.

5. Goudis CA, Ketikoglou DG. Obstructive sleep and atrial fibrillation: pathophysiological mechanisms and therapeutic implications. Int J Cardiol. 2017;230:293-300

6. Li T, Chen Y, Gua C, Wu B. Elevated oxidative stress and inflammation in hypothalamic paraventricular nucleus are associated with sympathetic excitation and hypertension in rats exposed to chronic intermittent hypoxia. Front Physiol. 2018:9:840

7. Gaines J, Vgontzas AN, Fernandez-Mendoza J, Bixler EO. Obstructive sleep apnea and the metabolic syndrome: the road to clinically-meaningful phenotyping, improved prognosis, and personalized treatment. Sleep Med Rev. 2018;42:211-9.

8. Ryan S. Adipose tissue inflammation by intermittent hypoxia: mechanistic link between obstructive sleep apnoea and metabolic dysfunction. J Physiol. 2017:595:2423-30
9. Olaithe M, Bucks RS, Hillman DR, Eastwood PR. Cognitive deficits in obstructive sleep apnea: insights from a meta-review and comparison with deficits observed in COPD, insomnia, and sleep deprivation. Sleep Med Rev. 2018;38:39-49..

10. Bucks RS, Olaithe M, Rosenzweig I, Morrell MJ. Reviewing the relationship between OSA and cognition: where do we go from here? Respirology. 2017;22:1253-61.

11. Dewan NA, Nieto FJ, Somers VK. Intermittent hypoxemia and OSA implications for comorbidities. Chest. 2015;147:266-74.

12. Kealy J, Murray C, Griffin EW, Lopez-Rodriguez AB, Healy D, Tortorelli LS Lowry JP, Watne LO, Cunningham C. Acute inflammation alters brain energy metabolism in mice and humans: role in suppressed spontaneous activity, impaired cognition, and delirium. J Neurosci. 2020.

13. Saresella M, Marventano I, Piancone F, La Rosa F, Galimberti D, Fenoglio C, Scarpini E, Clerici M. IL-33 and its decoy sST2 in patients with Alzheimer's disease and mild cognitive impairment. J Neuroinflammation. 2020;17:174.

14. Unnikrishnan D, Jun J, Polotsky V. Inflammation in sleep apnea: an update. Rev Endocr Metab Disord. 2015;16:25-34.

15. Song J-Q, Jiang L-Y, Fu C-P, Wu X, Liu Z-L, Xie L, Wu X-D, Hao S-Y, Li S-Q. Heterozygous SOD2 deletion deteriorated chronic intermittent hypoxiainduced lung inflammation and vascular remodeling through mtROS-NLRP3 signaling pathway. Acta Pharmacol Sin. 2020.

16. Puig F, Rico F, Almendros I, Montserrat JM, Navajas D, Farre R. Vibration enhances interleukin- 8 release in a cell model of snoring-induced airway inflammation. Sleep. 2005;28:1312-6.

17. Yilmaz Avci A, Avci S, Lakadamyali H, Can U. Hypoxia and inflammation indicate significant differences in the severity of obstructive sleep apnea within similar apnea-hypopnea index groups. Sleep Breath. 2017;21:703-11.

18. Guilleminault C, Kirisoglu C, Ohayon MM. C-reactive protein and sleepdisordered breathing. Sleep. 2004:27:1507-11.

19. Paulsen FP, Steven $P$, Tsokos $M$, Jungmann $K$, Muller A, Verse T, Pirsig W. Upper airway epithelial structural changes in obstructive sleep-disordered breathing. Am J Respir Crit Care Med. 2002;166:501-9.

20. Tobaldini E, Costantino G, Solbiati M, Cogliati C, Kara T, Nobili L, Montano N. Sleep, sleep deprivation, autonomic nervous system and cardiovascular diseases. Neurosci Biobehav Rev. 2017:74:321-9.

21. Vicente E, Marin JM, Carrizo SJ, Osuna CS, Gonzalez R, Marin-Oto M, Forner $M$, Vicente $P$, Cubero $P$, Gil AV, Soler X. Upper airway and systemic inflammation in obstructive sleep apnoea. Eur Respir J. 2016;48:1108-17.

22. Bhattacharjee R, Kim J, Kheirandish-Gozal L, Gozal D. Obesity and obstructive sleep apnea syndrome in children: a tale of inflammatory cascades. Pediatr Pulmonol. 2011;46:313-23.

23. Gaines J, Vgontzas AN, Fernandez-Mendoza J, Calhoun SL, He F, Liao D, Sawyer MD, Bixler EO. Inflammation mediates the association between visceral adiposity and obstructive sleep apnea in adolescents. Am J Physiol Endocrinol Metab. 2016;311:E851-e858.

24. Yu F-C, Yuan C-X, Tong J-Y, Zhang G-H, Zhou F-P, Yang F. Protective effect of sphingosine-1-phosphate for chronic intermittent hypoxia-induced endothelial cell injury. Biochem Biophys Res Commun. 2018:498:1016-21.

25. Song D, Fang G, Greenberg H, Liu SF. Chronic intermittent hypoxia exposure-induced atherosclerosis: a brief review. Immunol Res. 2015;63: $121-30$

26. Daulatzai MA. Evidence of neurodegeneration in obstructive sleep apnea: relationship between obstructive sleep apnea and cognitive dysfunction in the elderly. J Neuroscie Res. 2015;93:1778-94.

27. Huang Y-S, Guilleminault C, Hwang F-M, Cheng C, Lin C-H, Li H-Y, Lee L-A. Inflammatory cytokines in pediatric obstructive sleep apnea. Medicine. 2016;95.

28. Ciccone MM, Scicchitano P, Zito A, Cortese F, Boninfante B, Falcone VA Quaranta VN, Ventura VA, Zucano A, Di Serio F, et al. Correlation between inflammatory markers of atherosclerosis and carotid intima-media thickness in Obstructive Sleep Apnea. Molecules. 2014;19:1651-62.

29. Wu X, Chang SC, Jin J, Gu W, Li S. NLRP3 inflammasome mediates chronic intermittent hypoxia-induced renal injury implication of the microRNA-155/ FOXO3a signaling pathway. J Cellular Physiol. 2018;233:9404-15.

30. Zhang $C$, Dong $H$, Chen F, Wang $Y$, Ma J, Wang G. The HMGB1-RAGE/TLRTNF-a signaling pathway may contribute to kidney injury induced by hypoxia. Exp Ther Med. 2019:17:17-26.

31. Guo X, Shi Y, Du P, Wang J, Han Y, Sun B, Feng J. HMGB1/TLR4 promotes apoptosis and reduces autophagy of hippocampal neurons in diabetes combined with OSA. Life Sci. 2019;239:117020. 
32. Gabryelska A, Kuna P, Antczak A, Bialasiewicz P, Panek M. IL-33 mediated inflammation in chronic respiratory diseases-understanding the role of the member of IL-1 superfamily. Front Immunol. 2019;10:692.

33. Nadeem R, Molnar J, Madbouly EM, Nida M, Aggarwal S, Sajid H, Naseem J, Loomba R. Serum inflammatory markers in obstructive sleep apnea: a metaanalysis. J Clin Sleep Med. 2013;9:1003-12.

34. Bouloukaki I, Mermigkis C, Tzanakis N, Kallergis E, Moniaki V, Mauroudi E, Schiza SE. Evaluation of inflammatory markers in a large sample of obstructive sleep apnea patients without comorbidities. Mediators Inflamm. 2017;2017:4573756.

35. Bozic J, Borovac JA, Galic T, Kurir TT, Supe-Domic D, Dogas Z. Adropin and inflammation biomarker levels in male patients with obstructive sleep apnea: a link with glucose metabolism and sleep parameters. J Clin Sleep Med. 2018;14:1109-18.

36. Motamedi V, Kanefsky R, Matsangas P, Mithani S, Jeromin A, Brock MS, Mysliwiec V, Gill J. Elevated tau and interleukin- 6 concentrations in adults with obstructive sleep apnea. Sleep Medicine. 2018;43:71-6.

37. Svatikova A, Wolk R, Shamsuzzaman AS, Kara T, Olson EJ, Somers VK. Serum amyloid a in obstructive sleep apnea. Circulation. 2003;108:1451-4.

38. Sozer V, Kutnu M, Atahan E, Caliskaner Ozturk B, Hysi E, Cabuk C, Musellim B, Simsek G, Uzun $H$. Changes in inflammatory mediators as a result of intermittent hypoxia in obstructive sleep apnea syndrome. Clin Respir J. 2018;12:1615-22.

39. Chen CY, Chen CL, Yu CC, Chen TT, Tseng ST, Ho CH. Association of inflammation and oxidative stress with obstructive sleep apnea in ischemic stroke patients. Sleep Med. 2015;16:113-8.

40. Wu WT, Tsai SS, Shih TS, Lin MH, Chou TC, Ting H, Wu TN, Liou SH. The impact of obstructive sleep apnea on high-sensitivity C-reactive protein in subjects with or without metabolic syndrome. Sleep Breath. 2015:19:1449-57.

41. Briancon-Marjollet A, Henri M, Pepin JL, Lemarie E, Levy P, Tamisier R. Altered in vitro endothelial repair and monocyte migration in obstructive sleep apnea: implication of VEGF and CRP. Sleep. 2014;37:1825-32.

42. Gaines J, Vgontzas AN, Fernandez-Mendoza J, He F, Calhoun SL, Liao D, Bixler EO. Increased inflammation from childhood to adolescence predicts sleep apnea in boys: a preliminary study. Brain Behav Immun. 2017;64:259-65.

43. Rockstrom MD, Chen L, Taishi P, Nguyen JT, Gibbons CM, Veasey SC, Krueger JM. Tumor necrosis factor alpha in sleep regulation. Sleep Med Rev. 2018:40:69-78

44. Kheirandish-Gozal L, Gozal D. Obstructive sleep apnea and inflammation: proof of concept based on two illustrative cytokines. Int J Mol Sci. 2019:20.

45. Chen PC, Guo CH, Tseng CJ, Wang KC, Liu PJ. Blood trace minerals concentrations and oxidative stress in patients with obstructive sleep apnea. J Nutri Health Aging. 2013;17:639-44.

46. Taylor-Gjevre RM, Gjevre JA, Nair BV, Skomro RP, Lim HJ. Improved sleep efficiency after anti-tumor necrosis factor a therapy in rheumatoid arthritis patients. Ther Adv Musculoskelet Dis. 2011;3:227-33.

47. Khalyfa A, Serpero LD, Kheirandish-Gozal L, Capdevila OS, Gozal D. TNF-a gene polymorphisms and excessive daytime sleepiness in pediatric obstructive sleep apnea. J Pediatr. 2011;158:77-82.

48. Bhushan B, Guleria R, Misra A, Luthra K, Vikram NK. TNF-alpha gene polymorphism and TNF-alpha levels in obese Asian Indians with obstructive sleep apnea. Respir Med. 2009;103:386-92.

49. Kosmas CE, Silverio D, Sourlas A, Montan PD, Guzman E, Garcia MJ. Antiinflammatory therapy for cardiovascular disease. Ann Trans Med. 2019;7:147.

50. Akbari M, Hassan-Zadeh V. IL-6 signalling pathways and the development of type 2 diabetes. Inflammopharmacology. 2018;26:685-98.

51. Tegeler C, O'Sullivan JL, Bucholtz N, Goldeck D, Pawelec G, SteinhagenThiessen E, Demuth I. The inflammatory markers CRP, IL-6, and IL-10 are associated with cognitive function--data from the Berlin Aging Study II. Neurobiol Aging. 2016;38:112-7.

52. Wang Y, Mandelkow E. Tau in physiology and pathology. Nat Rev Neuroscience. 2016;17.

53. Bubu OM, Pirraglia E, Andrade AG, Sharma RA, Gimenez-Badia S, UmasaborBubu OQ, Hogan MM, Shim AM, Mukhtar F, Sharma N, et al. Obstructive sleep apnea and longitudinal Alzheimer's disease biomarker changes. Sleep. 2019:42.

54. Wang Y, Hu K, Liu K, Li Z, Yang J, Dong Y, Nie M, Chen J, Ruan Y, Kang J. Obstructive sleep apnea exacerbates airway inflammation in patients with chronic obstructive pulmonary disease. Sleep Med. 2015;16:1123-30.
55. Patruno V, Aiolfi S, Costantino G, Murgia R, Selmi C, Malliani A, Montano N. Fixed and autoadjusting continuous positive airway pressure treatments are not similar in reducing cardiovascular risk factors in patients with obstructive sleep apnea. Chest. 2007;131:1393-9.

56. Dorkova Z, Petrasova D, Molcanyiova A, Popovnakova M, Tkacova R. Effects of continuous positive airway pressure on cardiovascular risk profile in patients with severe obstructive sleep apnea and metabolic syndrome. Chest. 2008;134:686-92.

57. Jelic S, Padeletti M, Kawut SM, Higgins C, Canfield SM, Onat D, Colombo PC, Basner RC, Factor P, LeJemtel TH. Inflammation, oxidative stress, and repair capacity of the vascular endothelium in obstructive sleep apnea. Circulation. 2008;117:2270-8.

58. Kohler M, Stoewhas AC, Ayers L, Senn O, Bloch KE, Russi EW, Stradling JR. Effects of continuous positive airway pressure therapy withdrawal in patients with obstructive sleep apnea: a randomized controlled trial. Am J Respir Crit Care Med. 2011;184:1192-9.

59. Lin WC, Huang CC, Chen HL, Chou KH, Chen PC, Tsai NW, Chen MH, Friedman M, Lin HC, Lu CH. Longitudinal brain structural alterations and systemic inflammation in obstructive sleep apnea before and after surgical treatment. J Transl Med. 2016;14:139.

60. Schiza SE, Mermigkis C, Panagiotis P, Bouloukaki I, Kallergis E, Tzanakis N, Tzortzaki E, Vlachaki E, Siafakas NM. C-reactive protein evolution in obstructive sleep apnoea patients under CPAP therapy. Eur J Clin Invest. 2010:40:968-75.

61. Steiropoulos $P$, Kotsianidis I, Nena E, Tsara V, Gounari E, Hatzizisi O, Kyriazis G, Christaki P, Froudarakis M, Bouros D. Long-term effect of continuous positive airway pressure therapy on inflammation markers of patients with obstructive sleep apnea syndrome. Sleep. 2009;32:537-43.

62. Yokoe T, Minoguchi K, Matsuo H, Oda N, Minoguchi H, Yoshino G, Hirano T, Adachi M. Elevated levels of C-reactive protein and interleukin-6 in patients with obstructive sleep apnea syndrome are decreased by nasal continuous positive airway pressure. Circulation. 2003;107:1129-34.

63. Jin F, Liu J, Zhang X, Cai W, Zhang Y, Zhang W, Yang J, Lu G, Zhang X. Effect of continuous positive airway pressure therapy on inflammatory cytokines and atherosclerosis in patients with obstructive sleep apnea syndrome. Mol Med Rep. 2017;16:6334-9.

64. Wu K-M, Lin C-C, Chiu C-H, Liaw S-F. Effect of treatment by nasal continuous positive airway pressure on serum high mobility group box-1 protein in obstructive sleep apnea. Chest. 2010;137:303-9.

65. Kuramoto E, Kinami S, Ishida Y, Shiotani H, Nishimura $Y$. Continuous positive nasal airway pressure decreases levels of serum amyloid $A$ and improves autonomic function in obstructive sleep apnea syndrome. Int J Cardiol. 2009;135:338-45.

66. Ohga E, Tomita T, Wada H, Yamamoto H, Nagase T, Ouchi Y. Effects of obstructive sleep apnea on circulating ICAM-1, IL-8, and MCP-1. J Appl Physiol (1985). 2003;94:179-84.

67. Lu D, Li N, Yao X, Zhou L. Potential inflammatory markers in obstructive sleep apnea-hypopnea syndrome. Bosn J Basic Med Sci. 2017;17:47-53.

68. Tichanon P, Wilaiwan K, Sopida S, Orapin P, Watchara B, Banjamas I. Effect of continuous positive airway pressure on airway inflammation and oxidative stress in patients with obstructive sleep apnea. Can Respir J. 2016;2016:3107324.

69. Xie X, Pan L, Ren D, Du C, Guo Y. Effects of continuous positive airway pressure therapy on systemic inflammation in obstructive sleep apnea: a meta-analysis. Sleep Med. 2013;14:1139-50.

70. Wang J, Xu H, Guo C, Duan X, Hu F, Yang W, Cui J, Song L, Chun Y, Yuan J, Qiao S. Association between severity of obstructive sleep apnea and highsensitivity C-reactive protein in patients with hypertrophic obstructive cardiomyopathy. Clin Cardiol. 2020.

71. Colgan SP, Campbell EL, Kominsky DJ. Hypoxia and Mucosal Inflammation. Annu Rev Pathol. 2016;11:77-100.

72. Murphy AM, Thomas A, Crinion SJ, Kent BD, Tambuwala MM, Fabre A, Pepin $J$-L, Roche Helen M, Arnaud C, Ryan S. Intermittent hypoxia in obstructive sleep apnoea mediates insulin resistance through adipose tissue inflammation. Eur Respir J. 2017:49.

73. Biddlestone J, Bandarra D, Rocha S. The role of hypoxia in inflammatory disease (review). Int J Mol Med. 2015:35:859-69.

74. Nunes JOF, JdS A, DAG A, Ruiz FS, Fernandes ER, Andersen ML, Keller AC, Rosa DS. Sleep deprivation predisposes allergic mice to neutrophilic lung inflammation. J Allergy Clin Immunol. 2018;141.

75. Hurtado-Alvarado G, Dominguez-Salazar E, Pavon L, Velazquez-Moctezuma J, Gomez-Gonzalez B. Blood-brain barrier disruption induced by chronic 
sleep loss: low-grade inflammation may be the link. J Immunol Res. 2016; 2016:4576012

76. Almendros I, Acerbi I, Puig F, Montserrat JM, Navajas D, Farré R. Upperairway inflammation triggered by vibration in a rat model of snoring. Sleep. 2007;30:225-7

77. Li Z-L, Lv L-L, Tang T-T, Wang B, Feng Y, Zhou L-T, Cao J-Y, Tang R-N, Wu M, Liu $\mathrm{H}$, et al. HIF-1a inducing exosomal microRNA-23a expression mediates the cross-talk between tubular epithelial cells and macrophages in tubulointerstitial inflammation. Kidney Int. 2019;95:388-404.

78. Suresh MV, Balijepalli S, Zhang B, Singh W, Swamy S, Panicker S, Dolgachev VA, Subramanian C, Ramakrishnan SK, Thomas B, et al. Hypoxia-inducible factor (HIF)-1a promotes inflammation and injury following aspirationinduced lung injury in mice. Shock (Augusta, Ga). 2019;52:612-21.

79. Abe H, Semba H, Takeda N. The roles of hypoxia signaling in the pathogenesis of cardiovascular diseases. J Atheroscler Thromb. 2017;24: 884-94

80. Gileles-Hillel A, Almendros I, Khalyfa A, Nigdelioglu R, Qiao Z, Hamanaka RB, Mutlu GM, Akbarpour M, Gozal D. Prolonged exposures to intermittent hypoxia promote visceral white adipose tissue inflammation in a murine model of severe sleep apnea: effect of normoxic recovery. Sleep. 2017;40.

81. Pan W, Kastin AJ. Leptin: a biomarker for sleep disorders? Sleep Med Rev. 2014;18:283-90

82. Berger S, Polotsky VY. Leptin and leptin resistance in the pathogenesis of obstructive sleep apnea: a possible link to oxidative stress and cardiovascular complications. Oxid Med Cell Longev. 2018;2018:5137947.

83. Chin $\mathrm{C}-\mathrm{H}$, Lin $\mathrm{P}-\mathrm{W}$, Lin $\mathrm{H}-\mathrm{C}$, Friedman $\mathrm{M}$, Lin M-C. Effects of OSA surgery on leptin and metabolic profiles. Otolaryngol Head Neck Surg. 2019;161:1048-55

84. Irwin MR, Olmstead R, Carroll JE. Sleep disturbance, sleep duration, and inflammation: a systematic review and meta-analysis of cohort studies and experimental sleep deprivation. Biol Psychiatry. 2016;80:40-52.

85. Devaraj S, Davis B, Simon SI, Jialal I. CRP promotes monocyte-endothelia cell adhesion via Fcgamma receptors in human aortic endothelial cells under static and shear flow conditions. Am J Physiol Heart Circ Physiol. 2006;291:H1170-6

86. Feng YM, Thijs L, Zhang ZY, Yang WY, Huang QF, Wei FF, Kuznetsova T, Jennings AM, Delles $C$, Lennox R, et al. Glomerular function in relation to circulating adhesion molecules and inflammation markers in a general population. Nephrol Dial Transplant. 2018;33:426-35.

87. Diamond A. Executive functions. Ann Rev Psychol. 2013;64:135-68.

88. Dudai Y, Karni A, Born J. The consolidation and transformation of memory. Neuron. 2015;88:20-32.

89. Le Pelley ME, Mitchell CJ, Beesley T, George DN, Wills AJ. Attention and associative learning in humans: an integrative review. Psychological bulletin. 2016;142:1111-40

90. Lal C, Strange C, Bachman D. Neurocognitive impairment in obstructive sleep apnea. Chest. 2012;141:1601-10.

91. Vaessen TJ, Overeem S, Sitskoorn MM. Cognitive complaints in obstructive sleep apnea. Sleep Med Rev. 2015;19:51-8.

92. Bucks RS, Olaithe M, Eastwood P. Neurocognitive function in obstructive sleep apnoea: a meta-review. Respirology. 2013;18:61-70.

93. Sedky K, Bennett DS, Carvalho KS. Attention deficit hyperactivity disorder and sleep disordered breathing in pediatric populations: a meta-analysis. Sleep Med Rev. 2014;18:349-56.

94. O'Brien LM, Holbrook CR, Mervis CB, Klaus CJ, Bruner UL, Raffield TJ, Rutherford J, Mehl RC, Wang M, Tuell A, et al. Sleep and neurobehavioral characteristics of 5- to 7-year-old children with parentally reported symptoms of attention-deficit/hyperactivity disorder. Pediatrics. 2003;111: 554-63.

95. Mazza S, Pepin JL, Naegele B, Plante J, Deschaux C, Levy P. Most obstructive sleep apnoea patients exhibit vigilance and attention deficits on an extended battery of tests. Eur Respir J. 2005;25:75-80.

96. Karimi M, Hedner J, Zou D, Eskandari D, Lundquist AC, Grote L. Attention deficits detected in cognitive tests differentiate between sleep apnea patients with or without a motor vehicle accident. Sleep Med. 2015;16:528-33.

97. Tregear S, Reston J, Schoelles K, Phillips B. Obstructive sleep apnea and risk of motor vehicle crash: systematic review and meta-analysis. J Clin Sleep Med. 2009;5:573-81.

98. Lau EY, Choi EW, Lai ES, Lau KN, Au CT, Yung WH, Li AM. Working memory impairment and its associated sleep-related respiratory parameters in children with obstructive sleep apnea. Sleep Med. 2015;16:1109-15.
99. Twigg GL, Papaioannou I, Jackson M, Ghiassi R, Shaikh Z, Jaye J, Graham KS, Simonds AK, Morrell MJ. Obstructive sleep apnea syndrome is associated with deficits in verbal but not visual memory. Am J Respir Crit Care Med. 2010;182:98-103.

100. Kerner NA, Roose SP, Pelton GH, Ciarleglio A, Scodes J, Lentz C, Sneed JR, Devanand DP. Association of obstructive sleep apnea with episodic memory and cerebral microvascular pathology: a preliminary study. Am J Geriatr Psychiatry. 2017;25:316-25.

101. Wallace A, Bucks RS. Memory and obstructive sleep apnea: a meta-analysis. Sleep. 2013;36:203-20.

102. Mu L, Peng L, Zhang Z, Jie J, Jia S, Yuan H. Memory and executive screening for the detection of cognitive impairment in obstructive sleep apnea. Am J Med Sci. 2017:354:399-407.

103. Olaithe M, Bucks RS. Executive dysfunction in OSA before and after treatment: a meta-analysis. Sleep. 2013;36:1297-305.

104. Xia Y, Fu Y, Xu H, Guan J, Yi H, Yin S. Changes in cerebral metabolites in obstructive sleep apnea: a systemic review and meta-analysis. Sci Rep. 2016; 6:28712.

105. Zimmerman ME, Aloia MS. A review of neuroimaging in obstructive sleep apnea. J Clin Sleep Med. 2006;2:461-71.

106. Tummala S, Roy B, Park B, Kang DW, Woo MA, Harper RM, Kumar R. Associations between brain white matter integrity and disease severity in obstructive sleep apnea. J Neurosci Res. 2016;94:915-23.

107. Torelli F, Moscufo N, Garreffa G, Placidi F, Romigi A, Zannino S, Bozzali M, Fasano F, Giulietti G, Djonlagic I, et al. Cognitive profile and brain morphological changes in obstructive sleep apnea. Neuroimage. 2011;54:787-93.

108. Shi Y, Chen L, Chen T, Li L, Dai J, Lui S, Huang X, Sweeney JA, Gong Q. A meta-analysis of voxel-based brain morphometry studies in obstructive sleep apnea. Sci Rep. 2017;7:10095.

109. Chen HL, Lu CH, Lin HC, Chen PC, Chou KH, Lin WM, Tsai NW, Su YJ, Friedman M, Lin CP, Lin WC. White matter damage and systemic inflammation in obstructive sleep apnea. Sleep. 2015;38:361-70.

110. Filley $C M$, Fields RD. White matter and cognition: making the connection. J Neurophysiol. 2016;116:2093-104.

111. Dicks E, Tijms BM, Ten Kate M, Gouw AA, Benedictus MR, Teunissen CE, Barkhof F, Scheltens P, van der Flier WM. Gray matter network measures are associated with cognitive decline in mild cognitive impairment. Neurobiol Aging. 2018;61:198-206

112. Macey PM, Prasad JP, Ogren JA, Moiyadi AS, Aysola RS, Kumar R, Yan-Go FL, Woo MA, Albert Thomas M, Harper RM. Sex-specific hippocampus volume changes in obstructive sleep apnea. Neuroimage Clin. 2018;20:305-17.

113. Cross NE, Memarian N, Duffy SL, Paquola C, LaMonica H, D'Rozario A, Lewis SJG, Hickie IB, Grunstein RR, Naismith SL. Structural brain correlates of obstructive sleep apnoea in older adults at risk for dementia. Eur Respir J. 2018;52.

114. Kim H, Joo E, Suh S, Kim JH, Kim ST, Hong SB. Effects of long-term treatment on brain volume in patients with obstructive sleep apnea syndrome. Hum Brain Mapp. 2016;37:395-409.

115. Castronovo V, Scifo P, Castellano A, Aloia MS, ladanza A, Marelli S, Cappa SF, Strambi LF, Falini A. White matter integrity in obstructive sleep apnea before and after treatment. Sleep. 2014;37:1465-75.

116. Canessa N, Castronovo V, Cappa SF, Aloia MS, Marelli S, Falini A, Alemanno F, Ferini-Strambi L. Obstructive sleep apnea: brain structural changes and neurocognitive function before and after treatment. Am J Respir Crit Care Med. 2011;183:1419-26.

117. Miller MA. The role of sleep and sleep disorders in the development, diagnosis, and management of neurocognitive disorders. Front Neurol. 2015;6:224.

118. Zhang Y, Wang W, Cai S, Sheng Q, Pan S, Shen F, Tang Q, Liu Y. Obstructive sleep apnea exaggerates cognitive dysfunction in stroke patients. Sleep Med. 2017;33:183-90.

119. Stepan ME, Altmann EM, Fenn KM. Effects of total sleep deprivation on procedural placekeeping: More than just lapses of attention. J Exp Psychol Gen. 2019.

120. Kheirandish L, Gozal D. Neurocognitive dysfunction in children with sleep disorders. Dev Sci. 2006;9:388-99.

121. Zhou J, Camacho M, Tang X, Kushida CA. A review of neurocognitive function and obstructive sleep apnea with or without daytime sleepiness. Sleep Med. 2016;23:99-108.

122. Werli KS, Otuyama L, Bertolucci PH, Rizzi CF, Guilleminault C, Tufik S, Poyares D. Neurocognitive function in patients with residual excessive 
sleepiness from obstructive sleep apnea: a prospective, controlled study. Sleep Med. 2016;26:6-11.

123. Gagnon K, Baril AA, Gagnon JF, Fortin M, Décary A, Lafond C, Desautels A, Montplaisir J, Gosselin N. Cognitive impairment in obstructive sleep apnea. Pathol Biol. 2014;62:233-40

124. Gao H, Han Z, Huang S, Bai R, Ge X, Chen F, Lei P. Intermittent hypoxia caused cognitive dysfunction relate to miRNAs dysregulation in hippocampus. Behav Brain Res. 2017;335:80-7.

125. Xie H, Yung WH. Chronic intermittent hypoxia-induced deficits in synaptic plasticity and neurocognitive functions: a role for brain-derived neurotrophic factor. Acta Pharmacol Sin. 2012;33:5-10.

126. Shen YC, Kung SC, Chang ET, Hong YL, Wang LY. The impact of obesity in cognitive and memory dysfunction in obstructive sleep apnea syndrome. Int J Obes (Lond). 2019;43:355-61.

127. Vitelli O, Tabarrini A, Miano S, Rabasco J, Pietropaoli N, Forlani M, Parisi P, Villa MP. Impact of obesity on cognitive outcome in children with sleepdisordered breathing. Sleep Med. 2015;16:625-30.

128. Kung SC, Shen YC, Chang ET, Hong YL, Wang LY. Hypercapnia impaired cognitive and memory functions in obese patients with obstructive sleep apnoea. Sci Rep. 2018;8:17551.

129. Wang Z, Ying Z, Bosy-Westphal A, Zhang J, Schautz B, Later W, Heymsfield SB, Müller MJ. Specific metabolic rates of major organs and tissues across adulthood: evaluation by mechanistic model of resting energy expenditure. Am J Clin Nutr. 2010;92:1369-77.

130. Li H-Y, Tsai M-S, Huang C-G, Wang RYL, Chuang L-P, Chen N-H, Liu C-H, Hsu C-M, Cheng W-N, Lee L-A. Alterations in Alzheimer's disease-associated gene expression in severe obstructive sleep apnea patients. J Clin Med. 2019;8.

131. Randerath W, Bonsignore MR, Herkenrath S. Obstructive sleep apnoea in acute coronary syndrome. Eur Respir Rev. 2019;28.

132. Chen HL, Lin HC, Lu CH, Chen PC, Huang CC, Chou KH, Su MC, Friedman M, Chen YW, Lin WC. Systemic inflammation and alterations to cerebral blood flow in obstructive sleep apnea. J Sleep Res. 2017;26:789-98.

133. Sun L, Chen R, Wang J, Zhang Y, Li J, Peng W, Liu C. Association between inflammation and cognitive function and effects of continuous positive airway pressure treatment in obstructive sleep apnea hypopnea syndrome. Zhonghua yi xue za zhi. 2014;94:3483-7.

134. Haensel A, Bardwell WA, Mills PJ, Loredo JS, Ancoli-lsrael S, Morgan EE, Heaton RK, Dimsdale JE. Relationship between inflammation and cognitive function in obstructive sleep apnea. Sleep Breathing. 2009;13:35-41.

135. Dong P, Zhao J, Li N, Lu L, Li L, Zhang X, Yang B, Zhang L, Li D. Sevoflurane exaggerates cognitive decline in a rat model of chronic intermittent hypoxia by aggravating microglia-mediated neuroinflammation via downregulation of PPAR-y in the hippocampus. Behav Brain Res. 2018;347: 325-31.

136. Sapin E, Peyron C, Roche F, Gay N, Carcenac C, Savasta M, Levy P, Dematteis M. Chronic intermittent hypoxia induces chronic low-grade neuroinflammation in the dorsal hippocampus of mice. Sleep. 2015;38: 1537-46.

137. Shi Y, Guo X, Zhang J, Zhou H, Sun B, Feng J. DNA binding protein HMGB1 secreted by activated microglia promotes the apoptosis of hippocampal neurons in diabetes complicated with OSA. Brain, Behav Immunity. 2018;73:482-92.

138. Snyder B, Shell B, Cunningham JT, Cunningham RL. Chronic intermittent hypoxia induces oxidative stress and inflammation in brain regions associated with early-stage neurodegeneration. Physiol Rep. 2017;5.

139. Darnall RA, Chen X, Nemani KV, Sirieix CM, Gimi B, Knoblach S, McEntire BL, Hunt CE. Early postnatal exposure to intermittent hypoxia in rodents is proinflammatory, impairs white matter integrity, and alters brain metabolism. Pediatr Res. 2017;82:164-72.

140. Kim SM, Kim H, Lee JS, Park KS, Jeon GS, Shon J, Ahn SW, Kim SH, Lee KM, Sung JJ, Lee KW. Intermittent hypoxia can aggravate motor neuronal loss and cognitive dysfunction in ALS mice. PLoS One. 2013;8:e81808.

141. Block ML, Smith SMC, Friedle SA, Watters JJ. Chronic intermittent hypoxia exerts CNS region-specific effects on rat microglial inflammatory and TLR4 gene expression. PLOS ONE. 2013;8.

142. Deng Y, Yuan X, Guo X-I, Zhu D, Pan Y-y, Liu H-g: Efficacy of atorvastatin on hippocampal neuronal damage caused by chronic intermittent hypoxia: Involving TLR4 and its downstream signaling pathway. Respir Physiol Neurobiol 2015, 218:57-63.

143. Burckhardt IC, Gozal D, Dayyat E, Cheng Y, Li RC, Goldbart AD, Row BW. Green tea catechin polyphenols attenuate behavioral and oxidative responses to intermittent hypoxia. Am J Respir Crit Care Med. 2008;177: $1135-41$.

144. Lam CS, Tipoe GL, So KF, Fung ML. Neuroprotective mechanism of Lycium barbarum polysaccharides against hippocampal-dependent spatial memory deficits in a rat model of obstructive sleep apnea. PLoS One. 2015;10: e0117990.

145. Deng Y, Guo X-L, Yuan X, Shang J, Zhu D, Liu H-G. P2X7 receptor antagonism attenuates the intermittent hypoxia-induced spatial deficits in a murine model of sleep apnea via inhibiting neuroinflammation and oxidative stress. Chin Med J (Engl). 2015;128:2168-75.

146. Yuan X, Guo X, Deng Y, Zhu D, Shang J, Liu H. Chronic intermittent hypoxia-induced neuronal apoptosis in the hippocampus is attenuated by telmisartan through suppression of iNOS/NO and inhibition of lipid peroxidation and inflammatory responses. Brain Res. 2015;1596:48-57.

147. Row BW, Kheirandish L, Li RC, Guo SZ, Brittian KR, Hardy M, Bazan NG, Gozal D. Platelet-activating factor receptor-deficient mice are protected from experimental sleep apnea-induced learning deficits. J Neurochemistry. 2004; 89:189-96.

148. Skvarc DR, Berk M, Byrne LK, Dean OM, Dodd S, Lewis M, Marriott A, Moore EM, Morris G, Page RS, Gray L. 14 Post-operative cognitive dysfunction: an exploration of the inflammatory hypothesis and novel therapies. Neurosci Biobehav Rev. 2018:84:116-33.

149. Faden Al, Wu J, Stoica BA, Loane DJ. 13Progressive inflammation-mediated neurodegeneration after traumatic brain or spinal cord injury. $\mathrm{Br} J$ Pharmacol. 2016;173:681-91.

150. Balducci C, Frasca A, Zotti M, La Vitola P, Mhillaj E, Grigoli E, lacobellis M, Grandi F, Messa M, Colombo L, et al. Toll-like receptor 4-dependent glial cell activation mediates the impairment in memory establishment induced by $\beta$-amyloid oligomers in an acute mouse model of Alzheimer's disease. Brain Behav Immunity. 2017;60:188-97.

151. Chavan SS, Huerta PT, Robbiati S, Valdes-Ferrer SI, Ochani M, Dancho M, Frankfurt M, Volpe BT, Tracey KJ, Diamond B: HMGB1 mediates cognitive impairment in sepsis survivors. Molecular medicine (Cambridge, Mass) 2012, 18:930-937.

152. Abdullahi W, Tripathi D, Ronaldson PT. Blood-brain barrier dysfunction in ischemic stroke: targeting tight junctions and transporters for vascular protection. Am J Physiol Cell Physiol. 2018;315:C343-56.

153. Louveau A, Smirnov I, Keyes TJ, Eccles JD, Rouhani SJ, Peske JD, Derecki NC, Castle D, Mandell JW, Lee KS, et al. Structural and functional features of central nervous system lymphatic vessels. Nature. 2015;523:337-41.

154. Riedel B, Browne K, Silbert B. Cerebral protection: inflammation, endothelial dysfunction, and postoperative cognitive dysfunction. Curr Opin Anaesthesiol. 2014;27:89-97.

155. Terrando N, Eriksson LI, Ryu JK, Yang T, Monaco C, Feldmann M, Jonsson Fagerlund M, Charo IF, Akassoglou K, Maze M. Resolving postoperative neuroinflammation and cognitive decline. Ann Neurol. 2011;70:986-95.

156. Cheon SY, Kim JM, Kam EH, Ho C-C, Kim EJ, Chung S, Jeong J-H, Lee DD-H, Lee S-W, Koo B-N. Cell-penetrating interactomic inhibition of nuclear factorkappa B in a mouse model of postoperative cognitive dysfunction. Scientific Rep. 2017;7:13482.

157. Pan W, Stone KP, Hsuchou H, Manda VK, Zhang Y, Kastin AJ. Cytokine signaling modulates blood-brain barrier function. Curr Pharm Des. 2011;17: $3729-40$.

158. van Gool WA, van de Beek D, Eikelenboom P. Systemic infection and delirium: when cytokines and acetylcholine collide. The Lancet. 2010;375:773-5.

159. Dilger RN, Johnson RW. Aging, microglial cell priming, and the discordant central inflammatory response to signals from the peripheral immune system. J Leukoc Biol. 2008;84:932-9.

160. Kiernan EA, Smith SMC, Mitchell GS, Watters JJ. Mechanisms of microglial activation in models of inflammation and hypoxia: Implications for chronic intermittent hypoxia. J Physiol. 2016;594:1563-77.

161. Hong S, Beja-Glasser VF, Nfonoyim BM, Frouin A, Li S, Ramakrishnan S, Merry KM, Shi Q, Rosenthal A, Barres BA, et al. Complement and microglia mediate early synapse loss in Alzheimer mouse models. Science (New York, NY). 2016;352:712-6.

162. Flores KR, Viccaro F, Aquilini M, Scarpino S, Ronchetti F, Mancini R, Di Napoli A, Scozzi D, Ricci A. Protective role of brain derived neurotrophic factor (BDNF) in obstructive sleep apnea syndrome (OSAS) patients. PloS one. 2020;15:e227834.

163. Rothwell NJ, Luheshi G, Toulmond S. Cytokines and their receptors in the central nervous system: physiology, pharmacology, and pathology. Pharmacol Therapeutics. 1996;69:85-95. 
164. Li Z, Li B, Zhu X, Yin P, Liu J, Huang S, Sun R. Neuroprotective effects of anti-high-mobility group box 1 antibody in juvenile rat hippocampus after kainic acid-induced status epilepticus. Neuroreport. 2013;24:785-90.

165. Terrando N, Monaco C, Ma D, Foxwell BMJ, Feldmann M, Maze M. Tumor necrosis factor-alpha triggers a cytokine cascade yielding postoperative cognitive decline. Proc Natl Acad Sci USA. 2010;107:20518-22.

166. Barrientos RM, Hein AM, Frank MG, Watkins LR, Maier SF. Intracisternal interleukin-1 receptor antagonist prevents postoperative cognitive decline and neuroinflammatory response in aged rats. J Neurosci. 2012;32:14641-8.

167. Wongrakpanich S, Wongrakpanich A, Melhado K, Rangaswami J. A comprehensive review of non-steroidal anti-inflammatory drug use in the elderly. Aging Dis. 2018;9:143-50.

168. Peng M, Wang Y-L, Wang F-F, Chen C, Wang C-Y. The cyclooxygenase-2 inhibitor parecoxib inhibits surgery-induced proinflammatory cytokine expression in the hippocampus in aged rats. J Surg Res. 2012;178:e1-8.

169. Zhao W-X, Zhang J-H, Cao J-B, Wang W, Wang D-X, Zhang X-Y, Yu J, Zhang Y-Y, Zhang Y-Z, Mi W-D. Acetaminophen attenuates lipopolysaccharideinduced cognitive impairment through antioxidant activity. J Neuroinflammation. 2017;14:17.

170. Huang C, Irwin MG, Wong GTC, Chang RCC. Evidence of the impact of systemic inflammation on neuroinflammation from a non-bacterial endotoxin animal model. J Neuroinflammation. 2018;15:147.

171. Ning Q, Liu Z, Wang X, Zhang R, Zhang J, Yang M, Sun H, Han F, Zhao W, Zhang $X$. Neurodegenerative changes and neuroapoptosis induced by systemic lipopolysaccharide administration are reversed by dexmedetomidine treatment in mice. Neurological Res. 2017:39:357-66.

172. Zhu Y-J, Peng K, Meng X-W, Ji F-H. Attenuation of neuroinflammation by dexmedetomidine is associated with activation of a cholinergic antiinflammatory pathway in a rat tibial fracture model. Brain Res. 1644;2016:1-8.

173. Lindsberg PJ, Hallenbeck JM, Feuerstein G. Platelet-activating factor in stroke and brain injury. Ann Neurology. 1991;30:117-29.

174. Zager A. Modulating the immune response with the wake-promoting drug modafinil: a potential therapeutic approach for inflammatory disorders. Brain Behav Immun. 2020.

\section{Publisher's Note}

Springer Nature remains neutral with regard to jurisdictional claims in published maps and institutional affiliations.

Ready to submit your research? Choose BMC and benefit from:

- fast, convenient online submission

- thorough peer review by experienced researchers in your field

- rapid publication on acceptance

- support for research data, including large and complex data types

- gold Open Access which fosters wider collaboration and increased citations

- maximum visibility for your research: over $100 \mathrm{M}$ website views per year

At $\mathrm{BMC}$, research is always in progress.

Learn more biomedcentral.com/submissions 